\title{
"DEL ARCHIVO AL CONCIERTO": UN ITINERARIO PARA LA RECUPERACIÓN TEÓRICA Y PRÁCTICA DEL BARROCO MUSICAL HISPÁNICO.
}

\author{
“FROM THE ARCHIVE TO THE CONCERT”: \\ A ROADMAP FOR THE THEORETICAL AND PRACTICAL RECOVERY \\ OF HISPANIC MUSICAL BAROQUE
}

\author{
Antonio Ezquerro Esteban \& Marian Rosa Montagut \\ Departamento de Ciencias Históricas-Musicología, IMF (CSIC), Barcelona
}

\begin{abstract}
Resumen:
La ejecución sonora en la actualidad de la llamada "música antigua", supone una serie de "toma de decisiones" por parte del músico, que determinan unos itinerarios concretos, según se adopten o rechacen -para su plasmación sonora final- las diferentes posibilidades que salen al paso al investigador y al músico práctico. La elección por tanto, de uno u otro camino, determinará el tipo de interpretación final, más cercana a las fuentes documentales, o más liberada de trabas externas (más "artística"), o incluso, otros múltiples tipos de "soluciones de compromiso", a caballo entre las posturas más "historicistas" y aquellas otras supuestamente menos científicas, por más alejadas de las fuentes originales.

El presente estudio pretende aproximarse a los problemas que plantea el largo y complejo proceso de "rescate" sonoro de toda "nueva" música histórica (aquí conscientemente acotado al ámbito hispánico de los siglos XVII y XVIII), desde la localización documental de los manuscritos en los archivos, su transcripción, estudio y posterior edición crítica por parte del musicólogo, hasta su puesta en práctica por el músico con la interpretación pública en concierto.
\end{abstract}

Palabras clave:

Proceso de la investigación musical, puesta en práctica de la música antigua, interpretación musical históricamente informada, recuperación del patrimonio musical, Música y Musicología.

* Este artículo se ha realizado en el marco del Proyecto de Investigación del Plan Nacional de I + D + I: Orígenes y articulación de la Musicología hispánica en Europa. Felipe Pedrell (1841-1922) e Higinio Anglés (1888-1969). (HAR2008-06058/ ARTE). [El epígrafe "Del archivo al concierto" rememora el título de los cursos de doctorado y máster en Música impartidos conjuntamente por Antonio Ezquerro y Luis Antonio González en la Universidad Politécnica de Valencia, durante los cursos 2006-2011]. 


\begin{abstract}
:
The sound execution today of the "early music", means a series of "decision-making" by the musician, which determine specific itineraries as to adopt or reject (finally translating them sound) different possibilities come their way, the researcher and practical musician. The choice therefore, one way or another, determine the type of final interpretation, closer to documentary sources, or more free from external constraints (more "artistic"), or even multiple other types of "tradeoffs", halfway between the positions more "historicist" and those other supposedly less scientific, because of more distant from the original sources.

This study aims to approach the problems of long and complex process of "rescue" sound of any "new" historic music (here consciously limited the scope Hispanic seventeenth and eighteenth centuries), from locating manuscripts documentary files, transcription, study and subsequent critical edition by the musicologist, to its implementation by the musician through his public interpretation in concert.
\end{abstract}

Keywords:

Musical research process, implementation of early music, historically informed musical performance, musical heritage recovery, Music and Musicology.

El problema que se suscita ante la enorme multiplicidad de posibilidades expuestas que se le plantean al músico a la hora de "hacer" música (elegir una plantilla de instrumentos concreta, con un número de ejecutantes determinado y no otro, trabajando directamente a partir de la fuente o bien con un tipo de ediciones u otras, con un temperamento u otro, etc. etc.), es el de su mayor o menor validez.

En este sentido, conviene denunciar que, lamentablemente, no son pocos quienes, todavía hoy, cometen el error de, - dando un salto cualitativo al planteamiento descrito-, pretender que un tipo de "versión" (hay quien incluso llega a hablar de "la" versión, casi como la única posible o fidedigna al espíritu original del que emanó en un primer momento la composición) sea "mejor" o "peor" que otra, es decir, que se comete el error de pretender que un itinerario concreto implique un grado de calidad comparable con otro, aunque este último haya sido realizado a partir de un enfoque diametralmente diferente.

En los tiempos que corren en los que prácticamente todo se ha experimentado ya desde el punto de vista musical, todo está dicho, y hasta cierto punto, todo vale, tratar de discutir sobre qué cosa es mejor que otra (qué versión es la mejor, cuál la peor, etc.), no deja de ser una cuestión sin salida, pues implica una valoración estética, y como tal, tan extensa como individuos puedan entrar a valorarla (infinita). Diríase por tanto que no se trata de una cuestión "estética", cuanto de una cuestión de validez científica. Se puede tocar "música antigua" con criterios bien informados desde el punto de histórico (y en tal caso, hablaríamos de "hacer música histórica"), y se puede tocar esa misma música sin preocuparse en absoluto de los aspectos más puramente históricos, sino apenas fijándose en su resultado "artístico". Todo ello es viable (e incluso desde el punto de vista estrictamente estético al que antes nos referíamos, o desde un punto de vista "artístico", defendible y plausible), pero lo que parece claro es que, desde el punto de vista científico ("musicológico"), en el segundo ejemplo no deberíamos hablar de "música histórica”. En tal caso, a lo sumo, podríamos coincidir en que hacemos música rabiosamente contemporánea a nosotros, aunque a partir de unos materiales tomados prestados del pasado y manipulados libremente (y que, dependiendo de nuestro tipo de actuación, poco o nada tienen ya que ver, probablemente, con su sentido original). 
No obstante, hemos de ser conscientes de que eso no exime tampoco a las versiones "históricamente informadas" de un cierto grado de manipulación ${ }^{1}$, pues, por razones obvias, no contamos con certezas (ni con los recursos humanos del pasado - la formación de un músico actual no es la misma que la de un músico del Seiscientos o el Setecientos-, ni, a menudo, con todos los medios técnicos) ${ }^{2}$ sobre cómo sonó la música del pasado, y por lo tanto, en nuestras aproximaciones a ella, únicamente podremos ofrecer "una" propuesta concreta, resultado de una particular toma de decisiones, para la cual se habrán tenido que desechar opciones muy posiblemente también defendibles y aun plausibles desde el punto de vista histórico. De modo que, desde este punto de vista, también esta opción está sujeta a crítica y mejora. Pero, precisamente, ése es el "quid" de la cuestión: lo importante no es el qué, sino el cómo; más aún: lo importante no es el cómo, sino el por qué (encontrar argumentos defendibles para la versión escogida, de manera que si hacemos una versión "artística" el argumento sea puramente estético, y si optamos por una versión "históricamente informada”, el argumento no resulte anacrónico) ${ }^{3}$. El único problema, asumidas

1 Por otra parte, hay que tener en cuenta que ese tipo de manipulación ya existía en la época, pues una misma obra podía ejecutarse de maneras muy diversas en su propio momento (con diferentes cantores y/o instrumentistas, con un tipo concreto de temperamento u otro, variaciones en cuanto a lo que hoy identificamos como diapasón según las distintas condiciones climáticas de la estación del año y lugar concretos...), lo que implica que el musicólogo y el músico de hoy han de saber valorar qué tipo de manipulaciones podrían haber sido factibles en la época, y cuáles no.

2 Por ejemplo, no contamos hoy en día con cantantes castrados, ni sabemos con absoluta exactitud qué tensión se daba a las cuerdas de un instrumento concreto en un lugar concreto, ni disponemos del bagage y repertorio "asumidos" - y asentados de manera generalizada durante largos años de dedicación exclusiva a un tipo concreto de repertorio, lo que hoy en día sería impensable- por la mayoría de los cantores de canto llano de la época. Incluso, hoy en día, pretendemos ser más perfeccionsitas de lo que seguramente se era en la época -somos más "puristas"-, en múltiples cuestiones: temperamento, afinación, técnica instrumental y vocal, emisión sonora... Precisamente ese "purismo", es, por lo mismo que hemos señalado, lo menos purista. En todo caso, parece que buscamos hoy un "ideal" sonoro que nos ha sido transmitido por épocas posteriores (el cual arranca muy probablemente del Romanticismo), y en aras de dicho ideal pretendemos versiones más "perfectas" desde el punto de vista artístico y técnico-musical, aunque eso, a la postre, va seguramente en detrimento de lo propiamente histórico. Por otra parte, dadas las carencias "de partida" de cualquier intento de reconstrucción en la actualidad, musicólogos, músicos y sociedad en general, no pueden permitirse realizar versiones, acaso más históricas pero de una supuesta menor calidad (con cantores dotados de voces de calidad desigual, instrumentos técnicamente imperfectos, etc.), por lo que, acaso inconscientemente, la tendencia generalizada ha sido la de correr en busca de una música "ideal": se buscan versiones de la música de J. S. Bach que suenen casi perfectas, "a la manera de" Gardiner, Herreweghe u otros, y no meras aproximaciones a cómo pudo haber sonado el coro y orquesta de Santo Tomás en Leipzig, donde el Kantor se quejaba a menudo de los problemas vocales de sus niños, de las carencias técnicas de los instrumentistas a su cargo, etc. etc. (Se aduce aquí que, si Bach hubiera podido elegir, habría hecho música como en las versiones idealizadas que hoy día se ofrecen. Pero esto ¿ha de ser así?). Y sin embargo, precisamente, a las versiones citadas se las considera hoy en día como versiones "históricas"... (!?) Por tanto, el camino a emprender a partir de ahora, ¿debería dirigirse a hacer una música más "imperfecta"? ¿sería esto aceptable o aconsejable, según los condicionantes que nos autoimponemos en la sociedad actual? ... Lo evidente es que somos hijos del siglo XXI, que podría parecer absurdo la busca de un ideal sonoro "deficiente", y que, entretanto, han transcurrido casi tres siglos que no podemos borrar. No obstante, hemos también de ser conscientes de que las opciones hoy en día más generalizadas y que cuentan con mayor aceptación, por su alta calidad sonora, conducen a "tendencias" muy tecnológicas (por ej., los avances como los CDs de alta resolución, el MP3, etc. etc., que parecen desaconsejar el mínimo defecto -e incluso ruidos naturales como las respiraciones de los cantantes, el paso de las páginas...- en cuestiones de audio), algo menos artísticas, y poco científicas, que responden a las maneras y modos de pensar (y de evolucionar la sociedad) del siglo XX; y el siglo XXI ha de ser capaz de encontrar sus propios modos de expresión, que conjuguen, de manera equilibrada, la ciencia con el arte.

3 Yendo todavía un paso más allá: lo importante es, también, el qué. Qué se rescata, qué se toca, qué se canta, qué se escucha... y por qué eso precisamente y no otra cosa. En este sentido, la valoración positiva generalizada y asumida de un tipo de repertorio, hace que se acojan con mayor fluidez y benevolencia nuevas obras de esas mismas características; y por contraposición, el rechazo o acogida renuente de determinado tipo de obras, condiciona la recepción de nuevos títulos de características formales semejantes. Es decir, si la sociedad de los siglos XX y XXI nos ha acostumbrado a valorar como buena la música instrumental tipo "sonata", o "concierto", los nuevos títulos que podamos rescatar de las investigaciones en archivos que respondan más o menos al patrón o modelo "sonata" o "concierto", tendrán, a priorísticamente, - e incluso independientemente de su calidad intrínseca como obras individuales - , muchas posibilidades de ser bien acogidos por el público y la sociedad actual. En cambio, si no existe 
estas premisas, sería la confusión o amalgama de paradigma: mezclar lo estético con lo histórico, de donde, irremediablemente, surgiría la versión "anacrónica”.

Planteado hasta aquí el "status quaestionis", veamos a continuación algunas consideraciones generales respecto a nuestra propuesta de trabajo:

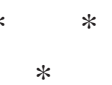

En nuestro "recorrido" «del archivo al concierto», conviene determinar unos planteamientos previos respecto al punto de partida. En primer lugar, conviene recordar que en el camino a seguir para el buen conocimiento de nuestra música pasada y nuestros músicos (nos referiremos aquí solamente a las primeras décadas del siglo XVIII en el contexto hispánico), se ha de contar irremediablemente con un proceso previo de búsqueda que conduzca a la localización y catalogación de las obras, su transcripción y edición, la confección de biografías críticas detalladas de los autores del momento, la edición de sus escritos teóricos -si es el caso-..., así como, finalmente, a la audición de dicha música mediante la inclusión de esas obras en conciertos y su grabación.

Por otra parte, como queda dicho, se ha de ser consciente de la imposibilidad de repetir o recrear fielmente la música pasada, pues, entre otras cosas, por su propia naturaleza, tan pronto como la música suena, desaparece. En este sentido, los mejores (¿únicos?) materiales que tenemos al respecto que nos transmiten cómo fue la música pasada, son los documentos (partituras, partichelas...), si bien éstos tampoco "son" aquella música, sino apenas un guión o una serie de pistas que el músico de hoy ha de saber "interpretar" con vistas a su reconstrucción. Es así como lo máximo a lo que el músico y musicólogo actual puede aspirar es a ofrecer una "aproximación" lo más cercana (fiel, informada, documentada....) posible a lo que la música pasada reflejada en los documentos pudo haber sido. Y en esta línea, con vistas a poder obtener una interpretación que se aproxime con todo el rigor posible a lo que pudo haber sonado en su momento (ya que no a su "realidad" pasada), resulta necesario, además, “contextualizar" al máximo las condiciones y el entorno en que dicha música "histórica" pudo haberse concebido, originado y producido. Para ello, es indispensable estudiar la amplia documentación auxiliar conservada en archivos y bibliotecas (actas capitulares, libros de pagos...), así como realizar un análisis organológico de los instrumentos utilizados -conservados- en dicho contexto en la época, estudiar los tratados teóricos coetáneos y, sobre todo, alcanzar la no siempre fácil y fluida comunicación y coordinación bidireccional entre musicólogos e intérpretes, dado que, en el momento de poner las obras estudiadas "en práctica", esto es, de interpretarlas, surgen una serie de problemas añadidos que no han

un hábito socialmente generalizado que considere como buena determinada música vocal (condicionada por unos textos, que, en función del idioma escogido, ofrecen un espectro geográfico difícilmente intercambiable o asumible por quienes no dominen ése idioma concreto), el rescate actual de composiciones de esas características, será, lógicamente, complejo, y estará sujeto a un muy lento - cuando se dé el caso - cambio de paradigma. Parece obvio, que hoy día es mucho más "vendible" determinado tipo de música instrumental, que no algunas composiciones vocales (del tipo villancico, u otras), particularmente cuando éstas son de carácter litúrgico (lamentaciones, salmos, himnos...), dado que su propia definición, "litúrgica", no es asumida de la misma manera por una audiencia católica, que por otras confesiones o creencias. 
aparecido durante el trabajo musicológico previo. Frente a ellos, resulta fundamental la nombrada coordinación estudiosos-intérpretes, sobre todo en el caso de la "toma de decisiones", no sólo en cuanto a los criterios estéticos sino, incluso, en cuanto a cuestiones mucho más "básicas", como la elección-en la ejecución- de los instrumentos a utilizar, del diapasón, del temperamento, de la realización de los acompañamientos cifrados, etc. que, evidentemente, al final hay que resolver en una "obligada" adaptación frente a las posibilidades de los recursos técnicos (instrumentos, salas de concierto y/o grabación, ...) y humanos (músicos con instrumentos originales y/o reproducciones de instrumentos de época válidos para las piezas concretas a interpretar, que tengan formación en los mismos así como en literatura musical histórica, ...), de que dispone el maestro/ director en la actualidad. Y siendo realistas, todo ello deberá conjugarse, además y sin más remedio, con la oferta/demanda impuesta por el mercado en cada momento (i.e., con la posibilidad que tenga el músico de obtener contratos o de conseguir recursos económicos que financien determinadas "apuestas serias"), o compaginarse, en ocasiones, con las exigencias de un público muy concreto (ávido a veces de "soluciones a la moda" o incluso de tipo "esnob") o de un gestor cultural interesado en "ofrecer espectáculo" - en el sentido de que, quien paga, pretende solicitar al músico práctico unas perspectivas "difícilmente negociables" desde el punto de vista más puramente histórico ${ }^{4}-$, etc. Ante semejante situación, el intérprete se encuentra frente a una encrucijada en la que ha de optar por dos posibles vías: una, asumir las exigencias impuestas en favor del "resultado" del momento - ya sea éste económico, de promoción laboral o "a la moda"...- y dos, no transigir, aun a sabiendas de que con ello corre el riesgo de no estar en condiciones de acceder a los recursos económicos indispensables (contratos, ofertas de concierto y/o grabación, ...) que posibiliten la interpretación de la música que se plantea, de un modo riguroso y con unos mínimos de calidad.

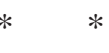

$*$

Ante el panorama al que el estudioso ha de enfrentarse en la actualidad, y teniendo en cuenta que, lamentablemente, no disponemos ya de la propia música tal y como pudo haber sonado en su día, contamos sin embargo con una herramienta fundamental para tratar de "re-construir" la música del pasado, la cual no siempre ha sido valorada como debiera: la tratadística y teoría musical de la época. Y, si bien es cierto que dicha tratadística tampoco puede suplir la carencia a la que hoy en día estamos abocados de los elementos puramente sonoros originales, sí que resulta imprescindible para nuestro conocimiento y mejor aproximación a las fuentes documentales, dado que los mencionados tratados fueron redactados - y esto es algo que a menudo se pasa por alto- por músicos prácticos, e incluso, a menudo, fueron redactados con una clara intencionalidad didáctica de enseñar (al que no sabía música, o a quien apenas contaba con unos rudimentos al respecto, para que alcanzara el grado más alto de capacidad técnica y especulativa en relación a la música, y con el mínimo esfuerzo).

4 No hay que perder de vista el hecho de que dichas exigencias, pueden suponer, a la postre, y más a menudo de lo deseable, el condicionante de mayor peso. 
Sin duda, cuando el músico práctico intenta hoy día reproducir las composiciones de las primeras décadas del siglo XVIII, se ve necesitado de una serie de consejos o indicaciones profesionales "de autoridad" que le ayuden a tomar sus propias decisiones, a partir de unos planteamientos bien argumentados, que proporcionen el mínimo rigor a sus actuaciones. Y naturalmente, cuando carecemos de la propia música original tal y como sonó, esto es francamente difícil y deviene, por consiguiente, en toda una suerte de aproximaciones, más o menos fieles al espíritu del que pudieron haber emanado tales obras musicales, y en las que, podría pensarse que, en cierto modo, todo vale. Pero eso no es exactamente así, por cuanto, el músico que "hace" música histórica de una manera consciente y bien meditada quiere, cada vez más, aportar a sus propuestas el mayor grado de "fiabilidad". Y en ese sentido, nada mejor que seguir las indicaciones y consejos que, sobre la materia, nos han transmitido los propios músicos prácticos a través de sus escritos, tratados, opúsculos manuscritos o impresos, y en general, en una documentación del tipo más variado (y que, precisamente, a partir de la época mencionada, comienza a proliferar en una suerte de literatura "menor": panfletos, pequeños escritos en el marco de polémicas artístico-musicales y literarias, cartas...). Es así como, cada "téorico" musical (entendido aquí el término teórico de la manera más amplia y flexible posible), da testimonio de las prácticas y usos de su entorno más cercano -incluso "local”, podríamos decir-, de manera que, en general y salvo excepciones, el teórico musical español aborda los temas y problemas que afectan más directamente a la música de su entorno, como también el alemán o el francés hacen lo propio con la música que se desarrolla en sus respectivos ambientes.

Responde por tanto este contexto de la tratadística musical europea a un cierto "nacionalismo" arraigado en la vieja Europa, el cual se va a dejar traslucir en algunos comentarios alusivos de los distintos teóricos. De este modo, no será infrecuente en los tratados del momento, hallar expresiones del tipo "los extranjeros... pero los españoles...”, de manera que la conclusión invariable era la de defender lo propio de cada lugar, en detrimento de lo foráneo.

El compositor y tratadista catalán Francisco Valls, poco antes de 1742, nos ofrece algunas muestras del mencionado espíritu "nacionalista":

“Acostumbran los Italianos trabajar sus obras no mas que á quatro vozes, y despues hecharle un ripieno (que es duplicar aquellas vozes, que viene á ser como un coro de capilla) lo que han tomado ya en España los compositores de poca monta, por ahorrar trabajo; entonces quando cantan todas las vozes, pueden entrar los violines, y todos los demás instrumentos que huviere con lo que se haze un Lleno de Musica muy bueno, que en Templos grandes sale admirablemente: pero advierta, que siempre que estas composiciones fueren á mayor numero de vozes, y sin ripienos, serán mas armoniosos, y tendran mas de Magisterio, que lo demas solo es bueno para la cortedad de las Capillas de musica, y siempre de los compositores. En cualquier composicion Eclesiastica, ô profana, hagase cargo el compositor, que lo principal de ella son las vozes, y que los instrumentos no son mas, que un adorno, que se le añade; y en este supuesto no aconsejo se siga la moda presente, que es empezar los instrumentos; con una introduccion, ô apertura muy larga, y las mas vezes impertinente, y, separada de la obra que se ha de cantar"’5.

5 PAVIA, 2002: capítulo XXVI "De las composiciones Musicas, con mezcla de varios Instrumentos", apartado II "Como se han de mezclar estos instrumentos con las vozes". [A pesar del ejemplo insertado, en el que F. Valls se muestra partidario de no seguir inopinadamente el criterio de los músicos italianos, no faltan tampoco en su tratado las alabanzas a la nueva música que entonces llegaba de Italia]. 
"No negaré, que los Franceses en composiciones Ecclesiasticas de tres, ó quatro vozes, tienen unos pensamientos delicados para la expression de la Letra aunque son muy prolixos en la repeticion de ella; [...] En Musica Ecclesiastica de pocas vozes tiene nuestra Española alguna semejanza con la Francesa. Exceden los Italianos a todas las Naciones en el buen gusto, é idea de la Musica Teatral vistiendo los affectos que exprime el verso con gran propriedad [...] en el Templo como se oye lo mismo y se dixo arriba muchas vezes será improprio. Pero ni Italianos, ni Franceses en sus composiciones Ecclesiasticas y aun en muchas de romance tienen lo que los Españoles de cientificas, y solidas, esto es tomar un Passo, ô Thema, y muchas vozes solo para una obra larga como una Missa; proseguirle con valentia, añadirle una, y muchas differentes intenciones, introducirla ahora un Canon, Fugas, Trocados, jugando los Baxos en los Coros armonicos, unas vezes imitandose unos â otros, otras remedandose acompañandoles las demas vozes, dexando aquella composicion perfectissima, y llena con 8. 10. û 12. vozes, y todas ordenadas con grande artificio, y gran limpieza de todo lo que prohibe el Arte acà en España: Estas circunstancias no se hallan en las Composiciones estrangeras, pues raras vezes passan de quatro a cinco vozes, y estas se duplican en los que llaman ripienos que sirven como de un Coro de Capilla que tambien se halla practicado por muchos Maestros Españoles porque no cuesta trabajo; pero faltale mas armonia. Y por ultimo lo que han procurado los Auctores Españoles es que su Musica sea agradable al oido, y deleyte el entendimiento del que es cientifico en ella"6.

Y no obstante, se producirá un cambio cualitativo y "de concepción” en la manera de entender la composición (el contrapunto y la armonía), evidente a partir de comienzos del siglo XVIII — aunque con diferente aplicación temporal según los distintos países y escuelas - . Así, la composición, ahora mucho más "moderna" (concebida "verticalmente", a partir de acordes y sus inversiones), hallará su principal valedor internacional en el francés Rameau $(* 1683 ; \uparrow 1764)^{7}$ y, para el caso hispánico, en José de Torres $(* 1670 \mathrm{c} ; \dagger 1738)^{8}$.

Entretanto, tampoco conviene perder de vista que, en este período concreto, van a convivir, en transición, el estilo "antiguo" más propiamente hispánico", con el nuevo estilo de moda, más "moderno" y en ascenso, y en gran medida venido de Italia, aunque también con algunos préstamos de Francia e incluso de la más lejana Alemania. Nos encontraremos entonces, con que los propios compositores, maestros de capilla, siguen la terminología anterior - la modalidad eclesiástica - para denominar las tonalidades de sus obras, e incluso con que utilizan los signos de compás más comunes en el siglo anterior; pero, al

6 Ibid., [introducción al tratado]. [Repárese en que la última frase de esta cita, alude probablemente al contexto en que se vio envuelto el propio F. Valls, a propósito de la polémica en torno a su célebre Missa Scala Aretina, por haber introducido en su "Gloria" una novena sin preparación, ajena a las reglas de la armonía entonces vigentes en ámbito hispánico. (Para la controversia de Valls, vid.: MARTÍN MORENO, 1976)].

7 RAMEAU, 1722. Su autor, uno de los máximos exponentes del emergente estilo galante, sentó en este trabajo las bases de la armonía moderna (a pesar de las críticas que recibió de J. J. Rousseau y otros músicos del momento), dando con ello un giro a los principios teóricos anteriores.

8 TORRES, [1702 y] 1736. Su autor, organista de la Real Capilla, además de notable editor de música y tratadista, trata aquí de la práctica del acompañamiento continuo, de los acordes, y de la introducción del nuevo estilo italiano en la música española. (Sobre la visión de la armonía y el contrapunto de los organistas de ámbito hispánico de la época, puede verse: DELGADO,2007).

9 Es decir, dotado de compases ternarios "de proporción" (frente a los "nuevos" compases concebidos ya como quebrados), con un vocabulario instrumental en regresión paulatina - para los ministriles-(frente a los "nuevos" instrumentos -violines, oboes, trompas-), unos esquemas formales escasamente novedosos -del tipo coplas y estribillo- (frente a los "nuevos" recitado y aria), unas técnicas constructivas ya gastadas -la policoralidad, como contraposición de masas-(frente a nuevos recursos "concertantes" -como alternancia de solos, grupos vocales o instrumentales concretos y el tutti-), etc. 
mismo tiempo, son capaces también de absorber la nueva tonalidad mayor-menor (con aparición "nueva" y progresiva de los sostenidos como alteraciones propias, de manera que éstos van a entender las nuevas tonalidades del sistema mayor-menor desde la nomenclatura de los viejos modos eclesiásticos, ahora "transportados"), y comienzan a utilizar los nuevos signos de compás y un tipo de notación "moderna" cada vez más idiomática para los instrumentos- que son, en su conjunto y en la práctica, las características fundamentales de la música que, (aunque en principio provocará cierto rechazo en el ámbito eclesiástico hispano), enseguida, se van a sancionar a nivel internacional -con la Escuela de Mannheim y los clásicos vieneses-, y que van a perdurar casi hasta nuestros días.

De hecho, la "convivencia" o el solapamiento de estas dos tendencias en la práctica originará, por otra parte, un nuevo problema, pues la coexistencia de "lo antiguo" y "lo moderno" hará que no todos los músicos españoles (aunque de un mismo contexto) entiendan la música práctica del mismo modo ${ }^{10}$. Por tanto, darán pistas sobre su interpretación que, a ojos de hoy, incluso en ocasiones pueden llegar a parecer contradictorias.

La cuestión era que, desde la Edad Media, en la práctica diaria del cantollano, la música de facistol, y en general, en toda la música religiosa, sobre todo en aquella con participación vocal, la música se había regido, en cuanto a su medida -en cuanto al concepto de "compás"-, por una serie de relaciones entre las distintas figuras mayores ${ }^{11}$ que, aunque habían dado lugar a diversas posibilidades para una misma "señal indicial” o signo de compás, ofrecían un único significado o solución, inequívoco, único, como si de una fórmula matemática se tratara. Eso sí, era preciso descifrar adecuadamente, previamente a la ejecución, esas señales indiciales o signos de compás.

A lo largo del siglo XVII, las relaciones utilizadas en la práctica de la composición, se redujeron notablemente, hasta el punto de quedar establecidos en el uso cotidiano apenas dos compases: el binario y el ternario $^{12}$. Estos compases se relacionaban de una manera "proporcional" (sesquiáltera, tripla...). En cambio,

10 De hecho, la aplicación de los principios teóricos o precisamente su no estricto cumplimiento, o el uso de nuevos recursos musicales novedosos "extranjeros" en las composiciones hispánicas de la época originó, en algunos casos, ciertas polémicas que, en general, pueden resumirse en discusiones entre, por una parte, los partidarios de lo "tradicional" (continuación del lenguaje propiamente hispánico del siglo XVII y cumplimiento de las reglas plasmadas en los tratados) y, por otra, los "modernos" (anteposición de la inspiración del artista frente a las reglas y/o inclusión de nuevos recursos llegados de Europa, como el uso de violines en la iglesia o del recitado y aria en los villancicos, etc.). De todas ellas, al parecer, la discusión que tuvo una mayor repercusión y difusión fue la conocida polémica en torno a la cuestión "Valls", originada a partir de una diferencia de parecer entre el propio Francesc Valls $(* 1665 ; \uparrow 1747)$, entonces maestro de capilla de la catedral de Barcelona, y el organista de la catedral de Palencia, Joaquín Martínez de la Roca $(* 1676 ; † 1756)$, sobre una disonancia sin preparar que aparecía en la "Missa Scala Aretina" del primero. [Vid.: LÓPEZ-CALO, 1968: 11-14, 22-26 y 70-72; y 1971: 109-116. SIEMENS, 1976-1977: 195-223. PAVIA, 1997. Y sobre las polémicas musicales españolas del siglo XVIII, en general: MARTíN MORENO, 1976: 365-379]. Por otra parte, los escritos del padre Benito Jerónimo Feijoo $(* 1676$; †1764) generaron numerosas polémicas, siendo motivo de muchas de ellas su discurso de 1726 "Música de los templos", en el que se quejaba de la influencia de la música italiana y la aplicación de sus procedimientos en la música española, sobre todo eclesiástica.

11 Como es bien conocido, la relación entre máxima y longa originaba el Modo mayor; la relación entre longa y breve, el Modo menor; entre breve y semibreve, el Tiempo; y entre semibreve y mínima, la Prolación; todo ello, con una múltiple combinatoria posible, dependiendo de que una o los dos de las figuras puestas en relación fuera perfecta (equivalente a tres figuras del valor inmediatamente menor a ella) o imperfecta (equivalente a dos figuras del valor inmediatamente menor).

12 Ambos con dos posibilidades: 1.- Para el binario: $\boldsymbol{a}$ ) compasillo o compás menor (C); y $\boldsymbol{b}$ ) compás mayor o partido $(\boldsymbol{\phi})$; y 2.- Para el ternario: $\boldsymbol{a})$ proporción menor $(\mathrm{C} 3 / 2)$; y $\boldsymbol{b})$ proporción mayor $(\not 3 / 2)$. En la práctica de la ejecución, esos signos de compás no se entenderán como los que utilizamos hoy en día, sino, más bien, como meras indicaciones del lugar donde han de ser colocados los acentos (y de ahí, de hecho, la coloración - los ennegrecimientos - a que se somete la notación en el caso de los 
con la cada vez mayor profusión de música instrumental, y los avances de la disciplina en las cortes y ámbito civil, fueron llegando a los territorios hispánicos nuevas maneras -foráneas-, de entender la composición, y con ellas, los compases, cada vez más concebidos en sí mismos y no tanto en su relación con los demás.

Así, los "guarismos" (en terminología de la época) que integraban algunos compases (anteriormente poco utilizados, pero ahora cada vez más), pasaron pronto a entenderse a manera de quebrados, donde el numerador indicaba el número de figuras que designaba el denominador (y así 3/4 equivalía a tres negras, $6 / 8$ a seis corcheas, etc., mientras en los compases antes referidos a la " $C$ " referencial, o a la " $\phi$ ", $3 / 2$ todavía significaba que, donde antes de este signo -según el denominador- entraban dos figuras al compás -es decir, donde antes teníamos un binario-, ahora, en el ternario -de acuerdo con el numerador-, y en el mismo lapso de tiempo, entrarán tres de la misma especie).

De este modo, los músicos de ámbito hispánico convivieron durante décadas con unos signos de compás heredados de la tradición (aquellos dotados de un círculo o un semicírculo, independientemente de que se les pudieran añadir guarismos, o no), a la vez que con unos "nuevos" signos de compás, meramente numéricos, y concebidos ya como quebrados (es decir, como en la actualidad) ${ }^{13}$. En ese contexto, precisamente, de solapamiento en el empleo de unos compases "antiguos" con otros "nuevos", y de la cada vez mayor influencia de estos últimos, algunos músicos prácticos pudieron haber llegado a olvidar o no comprender bien el concepto -la idea- de proporción que transmitían aquellos viejos compases. Podemos ver algunos casos en el mencionado tratado de Francisco Valls, en los cuales se puede apreciar fácilmente las diferentes equivalencias entre los ejemplos $a$ ) y $b$ ):

CASo 1: Diferentes maneras de entender una misma señal indicial o signo de compás en cuanto al empleo de líneas divisorias (y por lo tanto, a la aplicación de una determinada acentuación):

a) C6/8 = mínima con puntillo ${ }^{14}$.

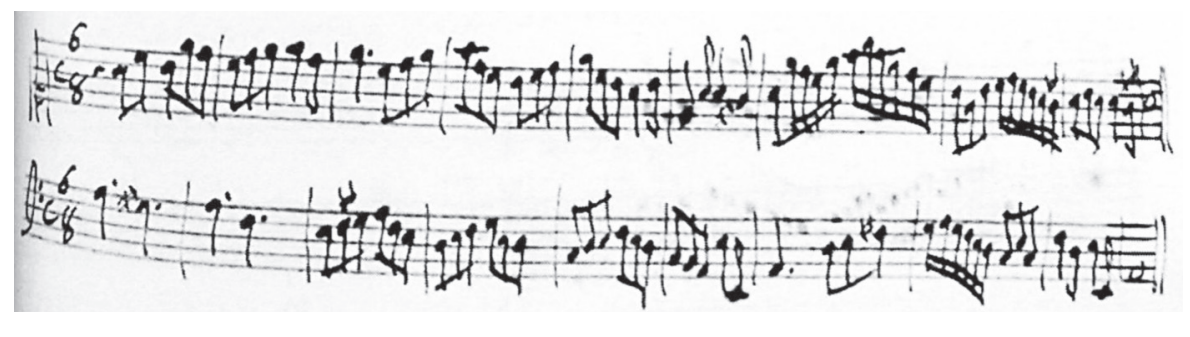

ternarios, al carecerse de líneas divisorias, para señalar síncopas y hemiolas y acentuar correctamente). Algunos autores como el organista y tratadista Andrés Lorente, llegarán incluso a decir en algún momento que solamente existían compases binarios, ya que los ternarios eran "reducibles" a regir el compás a dos partes, en las que se introducían tres tiempos, todos ellos de igual valor (a modo de nuestro actual "tresillo"). Vid.: GONZÁLEZ VALLE, 2002: Libro segundo, Nota XVI, "Que enseña las Diferencias que ay de Compases", pp. 220-221 (del facsímil), 270-271 (de la edición).

13 Estos últimos serían los que finalmente se impusieron, particularmente a partir de un cada vez mayor empleo de las líneas divisorias (que contribuyeron a delimitar física y espacialmente cada compás - en el sentido de "batuta"- entre dos líneas, constriñéndolo a un espacio del que ya no se podía salir - espacio que era anteriormente mucho más flexible-), y en definitiva, a partir de que se impusiera definitivamente la partitura como vía fundamental de transmisión musical (y ya no tanto, partichelas, libretes u otras múltiples disposiciones y formatos -de facistol, guiones...-).

14 PAVIA, 2002: Cap. XXXII, § 2: "De los tiempos mas modernos y su uso", fol. 226r. (p. 491 de la edición). 
ß) $\mathrm{C} 6 / 8=$ semínima con puntillo ${ }^{15}$.

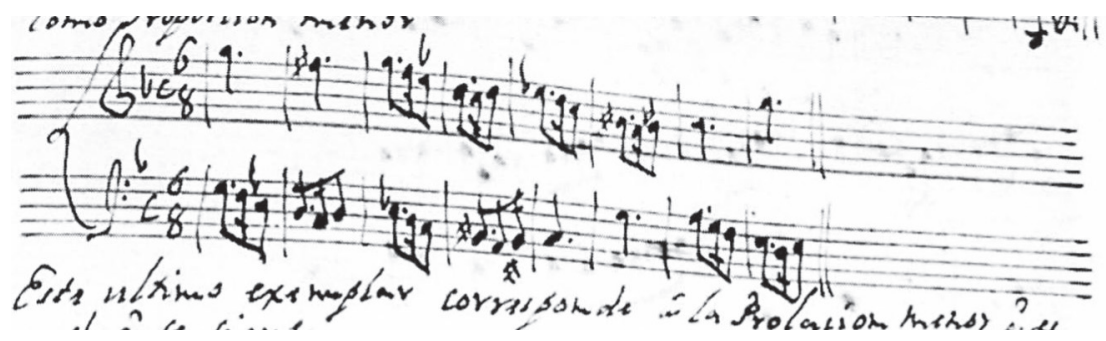

CASo 2: Diferentes maneras de entender una misma señal indicial, según la relación con otros compases:

a) (C) 6/4 en relación a $\mathrm{C}=$ semibreve $^{16}$.

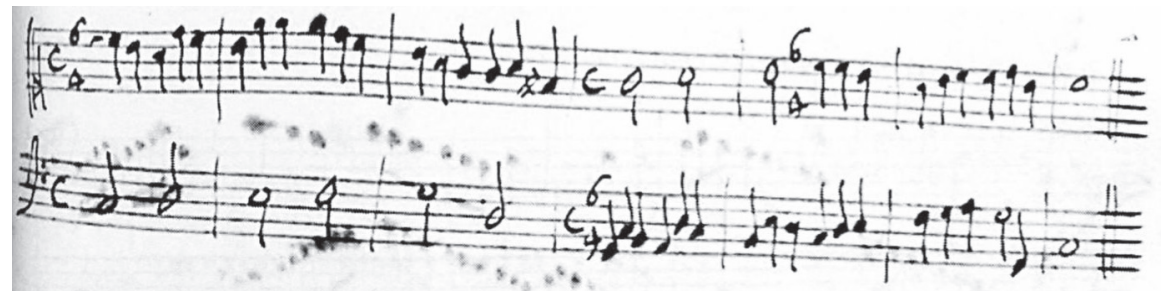

ß) (C) 6/4 en relación a (C) 3/4 = mínima con puntillo ${ }^{17}$.

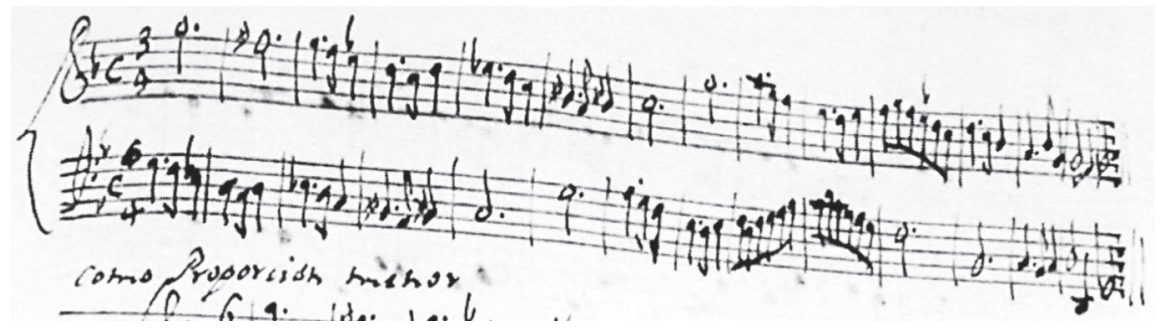

15 Íbid., fol. 227r. (p. 493 de la edición).

16 Íbid., fol. 226r. (p. 491 de la edición).

17 Íbid., fol. 227r. (p. 493 de la edición). 
CASO 3: En los siguientes dos ejemplos, en la señal indicial en la que el guarismo se refiere a la "C", aparecen seis semínimas al compás (a), mientras que, con idéntico guarismo, aunque referido a la " $\phi$ ", aparecen tres semínimas por compás (b); sin embargo, la equivalencia de cada ejemplo, se corresponde: con una breve en $a$ ), y con una mínima con puntillo en $b$ ).

a) (C) $6 / 4=$ breve $^{18}$.

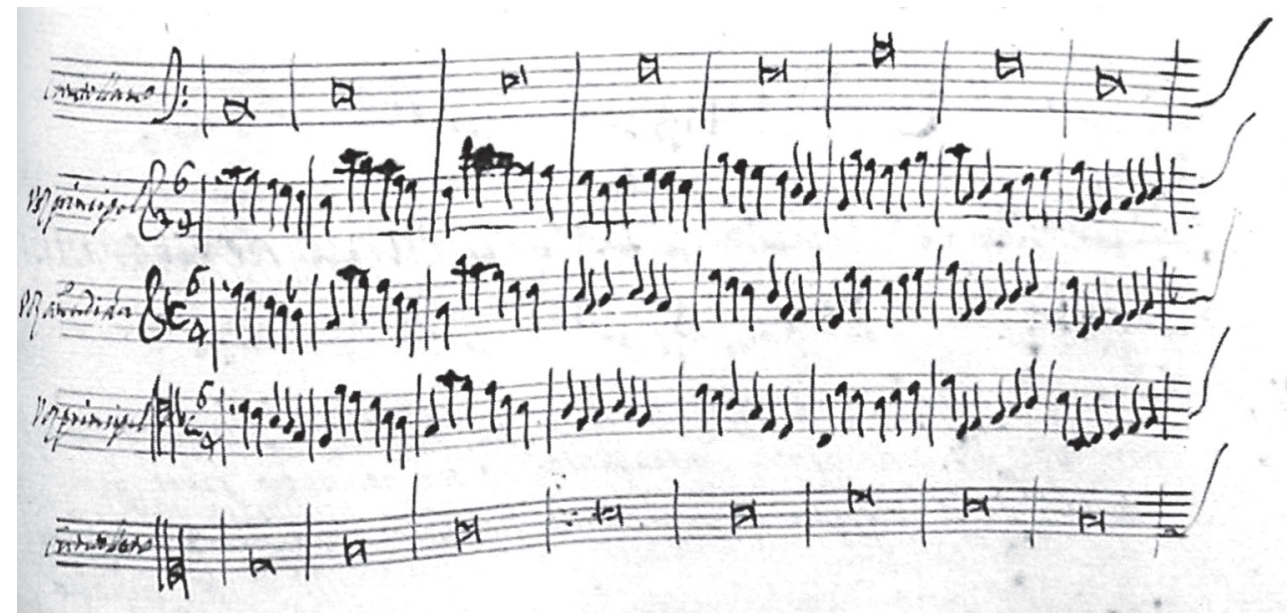

ß) (đ) $6 / 4$ = mínima con puntillo ${ }^{19}$.

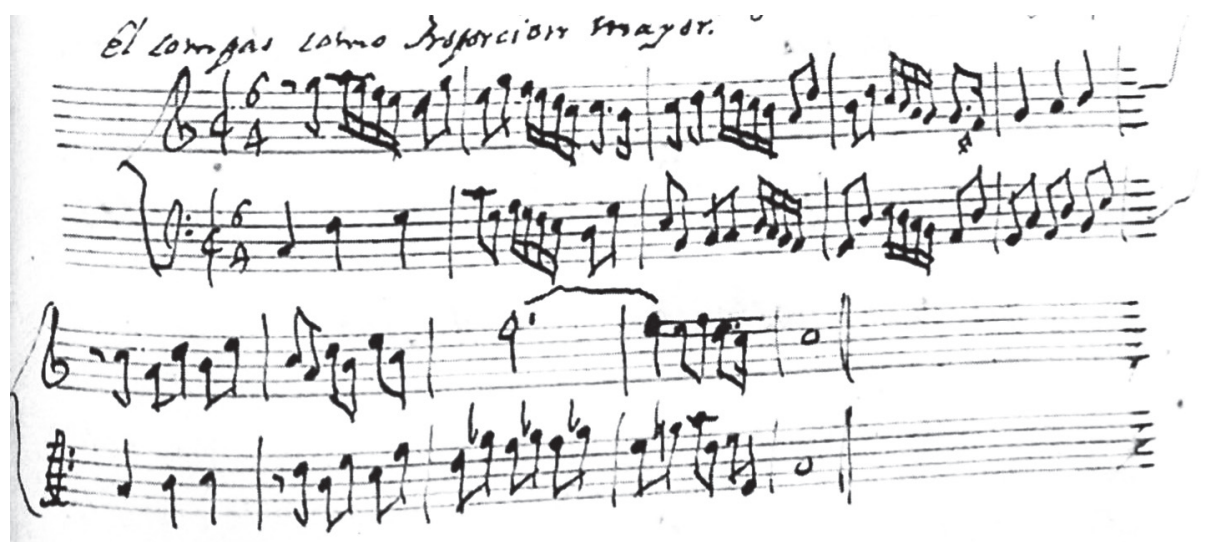

18 Íbid., Cap. 3, § II, "De los contrapuntos trocados", fol. 12r.-v. (pp. 63-64 de la edición).

19 Íbid., Cap. XXXII, § 2: "De los tiempos mas modernos y su uso", fol. 227r. (p. 493 de la edición). 
Los casos expuestos no son más que unos ejemplos seleccionados entre los múltiples posibles, pero dejan patente las grandes dificultades para aprehender la esencia de esta música y para poder realizar una “interpretación” adecuada - tanto teórica como práctica - de la misma, pues se trata de un lenguaje que, aparentemente, podría parecer muy sencillo (pues la notación es ya prácticamente como la actual), pero que, si se pretende profundizar en su estudio, plantea muchos más problemas de los que se hubieran podido sospechar en una primera impresión.

En este sentido, y como se ha visto, de igual modo que no existe una interpretación unívoca de la fuente musical, tampoco los tratados teórico-musicales, ni las fuentes documentales, a pesar de su enorme valor, nos ofrecen una solución universal a todas las cuestiones que hoy se nos plantean. Es por ello que se hace indispensable conjugar dichas vías de información, buscando el equilibrio entre las pistas que músicos y tratadistas nos ofrecen ${ }^{20}$. El estudio, por tanto, no sólo de las fuentes propiamente musicales, sino, muy especialmente, de la documentación auxiliar y de la tratadística, será un punto de apoyo fundamental para tratar de comprender, un poco mejor, el "contexto" de la música que se pretende recuperar; por otra parte, conviene recordar que la ejecución de dicho repertorio musical requiere, además, hoy, como siempre, de una cierta dosis de creatividad por parte del intérprete, que deberá aportar el imprescindible carácter artístico, que haga posible revivir dicha música.

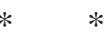

Una dificultad añadida con la que, además de lo anterior, deben enfrentarse hoy en día los músicos y los estudiosos, ante el rescate de la música de ámbito hispánico (incluido Latinoamérica) del pasado, y que sucede en menor grado en otros contextos occidentales, es la de que en los terrritorios regidos por la corona hispánica no se contó sino hasta fechas muy tardías con una imprenta musical especializada ${ }^{21}$.

20 Aparte los ya citados, conviene mencionar siquiera algunos otros tratados teórico-musicales de la época (sean sobre canto llano, canto de órgano, composición, instrumentos y/o danza), de entre los producidos en ámbito hispánico: NASSARRE, 1683 y 1700. Este famoso organista ciego del convento de San Francisco (Zaragoza) plasmó por escrito los principios y reglas generales de la música a partir de su experiencia como músico práctico. MARTÍN Y COLL, 1706. IDEM, 1707. IDEM, 1708. IDEM, 1709a. IDEM, 1709b. IDEM, 1714 y 1719. TOSCA, 1709. ULLOA, 1717. NASSARRE, 1724 y 1723. Este tratado retoma y mejora las ideas del primer tratado del organista zaragozano (Fragmentos Músicos), desarrollando, en dos volúmenes, el tema de los sonidos armónicos, sus divisiones y efectos, y exponiendo la doctrina del canto llano (de su uso en la iglesia) y del canto de órgano. BONASTRE, CLIMENT y MARTÍN MORENO, 1990.

21 A pesar de que existieron ejemplos muy destacados de volúmenes impresos de música en territorio peninsular, prácticamente desde la propia invención de la imprenta por Gutenberg, no sería hasta 1699 cuando se estableció en Madrid la llamada "Imprenta Real", regentada por el organista, compositor y maestro de la Real Capilla, José de Torres, especializada en la edición musical (y cuyo ejemplo más conocido fueron sus propias Reglas generales de acompañar, de 1702 y 1736), la cual iba a perdurar más de medio siglo. Éste, contribuyó considerablemente a la expansión de ediciones musicales en todo el ámbito hispánico, en tanto que inventó y desarrolló ciertas mejoras en el sistema tradicional de impresión. De su taller salieron, al menos, unos cuarenta impresos de gran importancia histórica, entre destacados títulos de música práctica (tonadas y minués "humanos" de Sebastián Durón; la fiesta real Destinos vencen finezas, de Juan de Navas, 1699 - que es una comedia en música con libreto de Lorenzo de las Llamas, que se representó en la corte para el cumpleaños de Carlos II-; un Missarum Liber, 1703, de su propia autoría -dedicado a Felipe $\mathrm{V}-$, siete misas de facistol, un Requiem, unas Canciones francesas de todos ayres para todos los instrumentos, 1705?, que son una especie de traducción española de las ediciones de danzas que hiciera Philidor a partir de obras de Lully, o la comedia armónica íntegramente cantada Los desagravios de Troya, 1712, de Joaquín Martínez de la Roca y con libreto de Juan 
Este hecho, debido a diferentes causas ${ }^{22}$ condicionó, acaso negativamente, una buena distribución y el más amplio impacto de las producciones hispánicas, particularmente fuera de su propio ámbito y entorno (cuando no, incluso, del ámbito particular y local para el que cada obra había sido escrita) ${ }^{23}$. Esto responde a una diferente manera de concebir la producción musical (condicionando así su consiguiente circulación y medios de difusión), no en términos de "industria" sino, más bien, en clave de "piezas de creación, únicas" 24 .

En este contexto, se ha de tener en cuenta que los cabildos eclesiásticos de ámbito hispánico, contaban para la parte vocal de Tiple con niños (reclutados en localidades cercanas, entre familias humildes y de demostrada religiosidad), quienes, al mudarles la voz en la adolescencia, dejaban de ser útiles para el servicio de la iglesia. No obstante, para garantizar la continuidad en el tiempo (para cubrir posibles bajas de músicos) del servicio musical cotidiano, se permitía a estos adolescentes -durante un breve período de tiempo- completar su formación con vistas a su futura ordenación, a cambio de realizar una serie de tareas

Francisco Escuder, que se imprimió en gran partitura orquestal, con todos los intermedios y danzas que acompañaban la representación), así como notables tratados de teoría musical (entre los cuales: NASSARRE, 1700. FERNÁNDEZ DE HUETE, 1702 y 1704. MONTANOS, 1712, 1728 y 1734. O GUZMÁN, 1709. ULLOA, 1717. Y MARTíN Y COLL, 1719. Todos ellos con sus correspondientes ejemplos musicales impresos en pauta).

22 "No se debió a una falta de desarrollo tecnológico sino a la existencia de una tradición fuerte sustentada en las mismas raíces de los medios de producción de la música en España. Así, la copia manuscrita continuó constituyendo, en los siglos XVI-XVIII, la mecánica más habitual de difusión de la música en el ámbito hispánico”. (EZQUERRO, GONZÁLEZ MARIN y GONZÁLEZ VALLE, 2008: 9-31).

23 Este tema puede verse ampliamente desarrollado en: EZQUERRO, GONZÁLEZ MARÍN y GONZÁLEZ VALLE, op. cit.

24 Téngase en cuenta además que los centros eclesiásticos que promovían la continua producción de música religiosa, no estaban interesados en que las obras de arte que costeaban se difundieran en otros lugares, pues depositaban en su creación un importante elemento de "innovación”. En el caso musical incluso se llegó a legislar en el sentido de que las composiciones que se hicieran en un templo concreto tuvieran que ser "nuevas para cada cada ocasión", garantizando así el impacto deseado sobre la audiencia. Es decir, el coste de la música que se iba a generar, se asumía en tanto en cuanto servía como vehículo para catequizar al pueblo. Se trataba de, por la vía de un entretenimiento aparentemente cándido o inocente, conmover afectivamente a una audiciencia expectante y ávida de novedades, con vistas a lograr su adoctrinamiento, en una síntesis de las tres funciones tradicionales del arte retórica del barroco: “docere, muovere \& delectare". Precisamente, esta intención de generar sorpresa (asombro, incertidumbre...) a través de la novedad y el ansiado espectáculo, exigía que las obras hubieran de ser únicas e intransferibles, individuales en sí mismas, y no-repetibles, pues el hecho de haberse reiterado habría invalidado su función de causar novedad/asombro y hubiera acabado con el suspense que, de este modo, se retroalimentaba de una ocasión a otra (cada Navidad se esperaban ansiosamente nuevos villancicos - o cada fiesta del Corpus, etc. - , cada Semana Santa se escuchaban nuevas lamentaciones...). Es más, incluso una vez logrado el objetivo perseguido (de novedad, impacto...), se pretendía que los materiales generados (partituras, papeles...) no se reprodujeran en otro lugar ajeno a aquél que los había generado; es decir, que, podría decirse que esto comportaba una idea de "propiedad", no sólo material, sino incluso, hasta cierto punto, también "intelectual" -en el sentido de propiedad por parte de la institución eclesiástica promotora de la obra musical, que será, de hecho, la dueña del proceso de creación artística: se ha compuesto una obra musical por su encargo, esta institución ha gestionado el momento y lugar para el que se ha escrito esa obra, ha pagado al compositor, al copiante, a los músicos que lo han interpretado, etc.-. La intención por tanto de que estas obras no "circularan" libremente llevó a que, poco a poco se fueran disponiendo medidas institucionales en el sentido de que, una vez ejecutada la obra en cuestión, sus papeles se depositaran bajo llave y se custodiaran convenientemente en el archivo (con la intención de poder volverlos a utilizar en caso necesario -o no-, acaso con la idea de, simplemente, contar con un repertorio músico-documental propio, que era fruto del esfuerzo técnico, humano y espiritual del centro que lo había promovido; en este último sentido, no hay que perder de vista que, del mismo modo que, salvando las distancias, una catedral no podía eliminar sin más un cáliz u otro objeto cualquiera que se había destinado a la liturgia, tampoco este tipo de materiales músico-documentales concebidos para la solemnización del culto, se podían desechar, destruir o transferir a otro lugar, sin que eso comportase al menos todo un protocolo institucional bien definido). A pesar de todo ello, tampoco se podía evitar que los creadores -compositores- recurrieran a ciertas argucias o picarescas para burlar la enorme carga de trabajo a que estaban sometidos, intercambiándose materiales por correo (con vistas a reaprovecharlos, adaptarlos, modificarlos, etc.), e incluso re-adaptando sus propias obras en otros lugares o contextos, o un tiempo prudencial después de que las hubieran escrito [sobre este último aspecto, véase: EZQUERRO y GONZÁLEZ MARÍN, 1991: 127-171]. 
"de apoyo" a la capilla de música, tales como suplir al organista, enseñar música a los infantes más pequeños, aprender a tocar algún instrumento, o ser aprovechados como copistas ("copiantes" o "puntadores") de música ${ }^{25}$. De este modo, se ayudaba a completar su ciclo de formación, y se les preparaba para que, en breve tiempo, pudieran revertir con sus servicios a ésa u otras capillas de música cercanas ${ }^{26}$.

Así, la copia de documentos resultaba más barata que la adquisición de obras impresas, se ejercitaba a los músicos en la caligrafía de su especialidad, y se les enseñaba -a través de un aprendizaje memorístico inconsciente, gracias al manejo habitual de los materiales musicales de diferentes maestros- los procedimientos, trucos de composición y rasgos distintivos de estilo de otros autores, al tiempo que todo esto servía para facilitar los papeles sueltos preceptivos -para cantores e instrumentistas- (Stimmblätter), los cuales iban a utilizarse en la ejecución musical práctica ${ }^{27}$, e iban a archivarse luego como documentos "primarios" (en el sentido de algo semejante a "originales").

Con este sistema de copia manuscrita, el mecenazgo musical eclesiástico lograba, además, agrupar y dar colocación provisional, en torno a la catedral, a un contingente de artesanos musicales especializado (copistas, libreros, restauradores...-incluso algunos eventuales compositores-, muchos de quienes debían conocer bien todos los detalles de la notación). Este mantenimiento de un grupo de personas "conoce-

25 En ocasiones, el puesto de copiante lo desempeñaba algún cantor o ministril de buena caligrafía, algún muchacho cantor que hubiera mudado la voz, o incluso, excepcionalmente, el propio maestro de capilla. Por otro lado, otras de las actividades relacionadas con la copia manuscrita de música de las que nos dan noticia los documentos y libros capitulares son los gastos tenidos por pagar a los iluminadores de los cantorales (los cuales, continuando con una tradición ininterrumpida que venía desde los scriptoria catedralicios medievales, se siguieron copiando hasta bien entrado el siglo XIX, y aun prefiriéndolos a las copias impresas), a los impresores de textos musicales (se editaron innumerables hojas volantes con los libretos de villancicos y oratorios), impresores propiamente de música, pergamineros, encuadernadores, etc. [Sobre la edición española de textos musicados en la época, y el interesante caso de su "circulación", ya se tratara de libretos de villancicos (que circularon no sólo por la España peninsular sino también por las posesiones de ultramar, incluido Nápoles, Sicilia y Cerdeña -Milán está por estudiar; en Florencia se conservan unos cancioneros-), ya de textos dramáticos (generalmente de comedias, que circulan traducidos al italiano y se utilizan como libretos de óperas -traducciones de Rospigliosi, Cicognini, etc.-), véanse: GUILLÉN y RUIZ DE ELVIRA SERRA, 1990. RUIZ DE ELVIRA SERRA, 1992. PAVIA, 1997: 39-167. TORRENTE y MARÍN, 2000.

26 En general, las tareas de copia se encomendaban, según la importancia de los centros, a personas específicas buscadas expresamente para ello, a las que se pagaba, bien de modo puntual, a modo de gratificación (es decir, no constando como trabajos remunerados regularmente o como puestos catedralicios en plantilla), o se cubrían -sobre todo a partir del siglo XVIII- bien plazas anexas a otras, bien medias plazas, o incluso cuartos de plaza (por ejemplo, una sola persona podía cubrir a la vez los puestos de violinista, oboista y copiante de música). Comoquiera que, generalmente, los copiantes no ocupaban cargos específicos para dicha tarea, y fijos, en plantilla, este cometido era a menudo realizado por algún cantor o ministril que tuviera buena caligrafía (como complemento de sueldo), e incluso por algún infante de coro, muchas veces el infante mayor, o estudiantes de gramática que habían cambiado la voz y a los que se mantenía de este modo a la espera de poder ofrecerles una plaza completa en propiedad. En algunas ocasiones, también los mismos maestros de capilla podían "sacar" sus propias copias a papeles, como parece ser el caso del maestro de capilla de la catedral de Zaragoza, Joseph Ruiz Samaniego ( $f$. 1653-1670). No está claro en cambio cuándo hacían esto los maestros (si en los lugares de importancia menor -con cabildos pequeños y exiguos recursos económicos-, si en determinadas composiciones, etc.: es un tema por estudiar). Pero en general, era el "copiante" el encargado de realizar las copias manuscritas de la composición musical en papeles sueltos, a partir de la tabula compositoria, o borrón, entregado por el maestro de capilla. (Cfr. EZQUERRO, 2002: 259-274).

27 Recuérdese, que, en esta época, la policoralidad iba a ser una de las modalidades de composición preferidas en el ámbito hispánico, lo cual presuponía la colocación de los diferentes coros, cantores e instrumentistas, en lugares diferentes de la iglesia, y de ahí la mayor comodidad, en la práctica, de contar con papeles sueltos, independientes, para cada parte. Muchas de las composiciones policorales manuscritas de la época, conservadas "a papeles", nos indican la ubicación exacta en la que debían situarse los intérpretes en la iglesia. Así por ejemplo, junto a los nombres de los ejecutantes que debían interpretar cada papel, las fuentes indican en ocasiones que los integrantes de un coro debían situarse, "a la tribuna", "al órgano mayor", "al organillo", etc, en una muestra evidente de los efectos estereofónicos y de teatralidad pretendidos. [Entre otros muchos casos que se podrían aducir, pueden verse algunos ejemplos en: EZQUERRO, 2000. Cfr. incipits musicales en p. 73 (E: Zac, B-56/824, del año 1655), p. 94 (E: Zac, B-14/277, del año 1656), o en p. 188 (E: Zac, B-7/115, del año 1656)]. 
doras" de la profesión musical (la composición, y otras actividades complementarias), en un ambiente próximo a la catedral, contribuía a la formación de jóvenes músicos y copistas, así como a mantener al día, a otras personas ya musicalmente formadas (monjes de scriptoria cercanos, cantores o ministriles avezados de la propia capilla musical catedralicia...), con vistas a echar mano de ellas si llegaba la ocasión (ausencia del maestro de capilla, deseo o necesidad capitular de hacerse con un repertorio determinado de difícil o costosa adquisición, etc.).

Por otro lado, es preciso poner en relación este tipo de procedimientos de copia con el hecho del escaso desarrollo de la industria impresora musical española de la época. Un hecho que sorprende mucho, sobre todo si tenemos en cuenta el poderío hispánico del momento y la fuerte implantación en la península ibérica de la imprenta desde poco después de la invención de Gutemberg ${ }^{28}$ (primero, con intención de abastacerse de composiciones para la solemnización del culto -manuales de carácter litúrgico-, y sólo después, de música polifónica ${ }^{29}$ e instrumental $)^{30}$.

28 El primer libro de música editado en España fue el Missale Caesaraugustanum, 1485, tan sólo doce años más tarde de que un taller anónimo publicara el primer libro de música, el Gradual de Constanza, en Alemania. También Sevilla contó con varios impresores alemanes y centroeuropeos (Magnus Herbs, Juan Pegnitzer, Pablo de Colonia, Tomás Glockner, Stanislao Polono o Meinardo Ungut), editando los cuatro primeros citados, en 1492, el primer libro español de teoría musical impreso: el tratado de DURÁN, 1492. En definitiva, podría decirse que el arte tipográfico español de los siglos XV y XVI fue uno de los más pujantes de Europa, gracias al temprano asentamiento en la península ibérica de impresores germanos y centroeuropeos (como, sólo por citar nuevamente el caso de una ciudad, como Zaragoza, los Enrique Botel, Jorge von Holtz, Juan Plank, Leonardo Hutz, Lupo Appenteger, Pablo y Juan Hurus, o Jorge Cocci). De sus oficinas salieron numerosos incunables, ya fueran biblias, misales, breviarios, o libros litúrgicos de canto con notación cuadrada (tonarios, pasionarios...), algunos de ellos todavía en vitela, aunque ya muchos en papel. Por otra parte, las imprentas de ciudades como Toledo, Salamanca, Valencia o Sevilla no eran menos activas en la época, de lo que dan buena cuenta numerosísimas obras entonces editadas, y de disciplinas tan variadas como la literatura, derecho, teología, ciencias... A pesar de lo anterior, sí es cierto en cambio, que la música que se editó desde un principio solía reducirse en su mayor parte al canto llano, por cuanto para imprimir música polifónica o instrumental se precisaban herramientas y tipos especializados, complejos y muy variados, de los que habitualmente no disponían las imprentas y oficinas españolas.

29 Tampoco puede decirse que la impresión de música polifónica española, aunque escasa, fuera inexistente. Se imprimió música de este tipo (ciertamente, no en cantidades comparables a otros lugares como Italia o Flandes), y cuando se hizo, se realizó con un alto nivel de calidad, en ediciones bien cuidadas. Por citar algunos ejemplos representativos, antes incluso del establecimiento de la Imprenta Real de José de Torres en 1699, encontramos los siguientes ejemplares impresos: VICTORIA, 1600. LOBO DE BORJA, 1602. VIVANCO, 1607. ESQUIVEL, 1608. AGUILERA, 1618. CORREA DE ARAUXO, 1626. SANZ, 1674...

30 En un principio, el interés por imprimir música de canto llano fue meramente utilitario, ya que hasta la aparición de la imprenta, y obviamente incluso mucho tiempo después, este tipo de música, litúrgica, se transmitía de forma manuscrita, para lo cual no se reparaban gastos en copias cuidadas, lujosamente encuadernadas e incluso iluminadas. Pero tras la invención de Gutemberg, la Corona española descubrió unos territorios vastísimos (en América, Oceanía...) que se propuso evangelizar, objetivo para el que la música desempeñaba un papel fundamental, generando una demanda inmediata y urgente, para la que la copia manuscrita ya no daba abasto. Conviene tener en cuenta en este sentido que, sin duda, desde el primer momento en que los españoles pusieron el pie en América, la música tuvo una presencia destacada (seguramente, al celebrarse una misa con su correspondiente Te Deum en acción de gracias), que se iría extendiendo rápidamente, conforme los europeos llegados se fueron distribuyendo por el nuevo continente. Es decir, que en la cultura y sociedad española del momento, la música era tan inherente a la religión católica, que en ningún caso un proceso de evangelización podría ser concebido sin ésta; es más, teniendo en cuenta que la población indígena no comprendía el idioma castellano, aunque sí el internacional de la música -según sus prácticas y costumbres particulares-, seguramente los españoles se ganaron antes a la población indígena a través de la música, que no por el verdadero conocimiento de los textos litúrgicos. Se hubo de echar mano entonces -sólo en un primer momento, hasta que, a imitación de la metrópoli, se consiguiera crear la infraestructura necesaria para que se pudieran sacar buenas copias manuscritas en los nuevos territorios-, de copias impresas, para proveer a las nuevas iglesias levantadas en los nuevos territorios de los imprescindibles libros litúrgicos, dotados a su vez del preceptivo cantollano para solemnizar la liturgia. Esto acarreó, evidentemente, la "uniformidad" de todos los ejemplares impresos, de manera que la posibilidad de contar con grandes tiradas cumplió una función valiosísima, al regularizar la evangelización, y con ello, la cultura española, en los territorios más vastos conocidos hasta la fecha. Con el paso del tiempo, cuando las nuevas iglesias ya estaban levantadas o muy avanzadas -a partir del siglo XVII-, se crearon allí también capillas musicales a imitación de las españolas (con sus "copiantes", etc.), de modo que la anterior urgencia desapareció y el procedimiento de intercambio de composiciones se hizo como en la península ibérica. 
Por concluir con este tema, el hecho de que no existieran talleres tipográficos de relevancia en territorio hispánico, y de que no se desarrollara una imprenta específicamente musical, no responde a que, llegado el caso, no hubiese medios económicos para ello, sino, más bien, a que los servicios que estas imprentas podían generar no eran necesarios en el "mercado" de aquel momento ${ }^{31}$. A todo lo dicho, habría que añadir además el hecho de que estaba "de moda", entre la sociedad española de la época (exportadora de materias primas - del mundo agrícola o ganadero-), importar encajes de Flandes, productos "exóticos" llegados de América, u otros productos manufacturados del exterior europeo (ingleses, franceses, alemanes...), sobre todo aquellos considerados "de lujo", por lo que era frecuente que entre dichos productos se hallasen impresos musicales ${ }^{32}$.

Visto todo esto desde una perspectiva puramente mercantil, en la producción y recepción/difusión de música impresa o manuscrita no sólo influyeron cuestiones de importación, sino que también entraron en juego cuestiones de exportación. Si bien es cierto que llegaron a la península materiales musicales procedentes de diferentes lugares de Europa, ciertos focos de producción musical situados en la península (más las islas Baleares y Canarias) ejercieron a su vez como difusores, no sólo de música europea no-hispánica, sino, sobre todo, de la música producida en su propio suelo. En este sentido, no cabe duda de que la corona hispánica exportó a sus nuevos territorios “de ultramar” no sólo músicos profesionales y aficionados (maestros y compositores, cantores, instrumentistas, organeros, constructores de todo tipo de instrumentos...), sino también "música” (y no sólo impresos, sino, fundamentalmente, manuscritos: cantorales, libretes, música a papeles), así como, sobre todo al principio, diversos instrumentos musicales (arpas, chirimías, bajones, etc.), e incluso los primeros grandes órganos catedralicios (por ejemplo, el de la catedral de México) ${ }^{33}$.

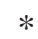

31 Cuestión aparte es la música instrumental (para tecla, arpa, vihuela...) -a menudo de consumo más individual o doméstico-. En este caso concreto, frente a la práctica inexistencia de talleres editoriales específicamente musicales en territorio peninsular, y de cara a facilitar el uso por parte de los aficionados, se adoptaron soluciones imaginativas con variados sistemas de notación musical en cifra.

32 Entre los impresos musicales editados en el exterior encontramos tanto algunos de compositores españoles, como de fuera, que se solían adquirir, muy particularmente, de Italia (Roma, Venecia, Nápoles...), Flandes (Amberes, Amsterdam) o París. Repárese que, aparte de los dos únicos referentes internacionales "inmutables" para España hasta bien entrado el siglo XX (Roma, como capital religiosa desde la que se emanaba doctrina a un país mayoritariamente católico como España: el Vaticano; y París, como la principal capital de la sociedad "civil" europea), o del caso veneciano -constituido prácticamente en dueño de un auténtico monopolio de edición musical, que copaba los mercados-, el resto de lugares citados quedaban asimismo bajo el cetro de la monarquía hispánica: Nápoles y Flandes. Por tanto, en estos últimos casos, no se trataba propiamente de "importaciones" de productos del extranjero, sino, más bien, de compra de artículos manufacturados y especializados procedentes de otros territorios de la Corona, aunque provistos del factor de lejanía o exotismo, lo que podía contribuir a su alta valoración. Ofrecemos a continuación una muestra de ediciones de música española impresa en el exterior: RAVAL, 1600. RIMONTE, 1614. ARANIÉS, 1624. BRICEÑO, 1626. SELMA, 1638. CASTRO, 1695...

33 La construcción de instrumentos se exportaría a América en un proceso definible en tres fases, para las cuales el órgano de la metropolitana del virreinato de la Nueva España resulta paradigmático: $1^{a}$ fase) El primer órgano destinado a la ciudad de México, y que se ubicaría en el lado de la Epístola de su catedral, fue encargado en 1688 al maestro organero aragonés Jorge de Sesma, siendo realizado íntegramente en territorio peninsular español (iniciado por el mencionado Sesma, tras su muerte en 1690 , sería continuado por su taller). La construcción de aquel monumental instrumento finalizó en 1693, a partir de cuando se procedió a su embarque y traslado en los galeones de la flota a América, precisándose desde entonces otros dos años de trabajo "in situ", hasta su definitiva puesta en servicio en $1695.2^{a}$ fase) Sólo con posterioridad, ya en 1735, se haría un nuevo instrumento para el mismo 
Hasta ahora hemos abordado algunos aspectos relacionados con las especificidades concretas de la música en el ámbito hispánico, particularmente en lo que atañe al período barroco y a su herencia o tradición musical precedente. En el marco del itinerario que el músico práctico actual ha de recorrer para aproximarse con garantías a las fuentes que se han conservado -con las que necesariamente habrá de trabajar-, hemos analizado diversos aspectos relacionados con la "producción" musical, sus vías de distribución y difusión, o el contexto en que estas obras se solían materializar. Sin embargo, la transmisión musical del pasado no sólo se ha recibido por vía de la propia fuente musical, o de la documentación e instrumentario que han pervivido sino que, muy posiblemente, las mejores herramientas de que disponemos hoy en día al respecto son los escritos "teóricos" -los tratados- elaborados por los propios músicos prácticos, por cuanto en ellos se concentra el "pensamiento" musical de un entorno y un momento histórico concretos, plasmable (eso sí, con mayor o menor fortuna) en las composiciones que nos han llegado. Precisamente, estos escritos $^{34}$ nos aportan en numerosas ocasiones las claves para descifrar muchos enigmas e interrrogantes planteados por las fuentes, bien entendido que no todos los tratados sirven para intentar solucionar problemas universalmente (en todo momento y lugar), sino que se ha de ajustar muy bien su mayor o menor aplicabilidad. En este sentido, ha de considerarse que, por ejemplo, no será adecuado aplicar las normas que ofrezca un tratado alemán del siglo XVII, para resolver determinados problemas derivados de la música práctica de ámbito hispánico del mismo período; como lo mismo ocurrirá en el caso contrario.

Sea como fuere, es evidente que existe una gran diferencia entre escribir música y escribir "sobre" música. En el primer caso, el compositor o creador no "controla" todos los factores que intervienen en hacer que su propia obra de arte "viva" (suene): el cantor glosará o adornará lo que él ha escrito, el continuista realizará de tal o cual modo la mera línea del bajo, etc., de manera que el resultado final será el fruto de un cúmulo de factores -exógenos-, y en ningún caso será competencia plena y exclusiva del compositor. En cambio, en el segundo caso citado, el escritor sobre música (es decir, el tratadista o teórico musical), "controla" plenamente todo el proceso de su transmisión del saber musical: es él quien habla, explayándose en la expresión de su pensamiento, lo que, seguramente, conseguirá -mediante el lenguaje escrito-, con mayor definición (o si se quiere, con mayor concreción, nitidez, etc., es decir, quedando menos sujeto a manipulación), que mediante un lenguaje inaprehensible, como es el de los sonidos.

templo (lado del Evangelio), y a cargo de un maestro organero asimismo aragonés, José Nassarre, quien, desplazado "ex profeso" a dicho lugar, realizaría ahora la construcción de dicho órgano plenamente en territorio mexicano. $3^{a}$ fase) A partir del momento citado, serán ya artesanos autóctonos mexicanos quienes (tras haber aprendido y haberse ejercitado en la profesión primeramente con organeros llegados de la penínusla) se encarguen de visurar, reparar, afinar, modificar, ampliar, y en definitiva, adaptar los instrumentos a las necesidades de los nuevos tiempos, e incluso, con el paso de los años, de constrtuir nuevos instrumentos en su totalidad. [Véase: DELGADO, 2005: 41-70. GUZMÁN BRAVO, 2007: 125-169]. Repárese bien en que, si la corona hispánica era entonces capaz de financiar la monumentalidad de semejante empresa -apenas por mencionar un ejemplo significativo-, bien habría sido capaz de costear el mantenimiento de las imprentas especializadas en música que hubieran sido precisas. Cabe suponer, por tanto, que éstas no se hubieran implantado no por motivos económicos, sino, más bien, por una falta de necesidad y de mercado, tal y como se ha ido viendo a lo largo del presente estudio.

34 Los tratados teóricos de ámbito hispánico nos han llegado tanto de forma impresa (P. Cerone, A. Lorente, P. Nassarre, J. de Torres...), como manuscrita. Curiosamente, los dos principales tratados de la primera mitad del siglo XVIII que nos han llegado de forma manuscrita, fueron escritos por músicos catalanes, llegando a alcanzar cierta difusión entre los maestros de capilla a nivel de territorios españoles, e incluso del otro lado del Atlántico: se trata de la Guía para los principiantes (1724-1738), de Pere Rabassa, y del Mapa Armónico (1742c), de Francesc Valls. [Vid.: BONASTRE, CLIMENT y MARTÍN MORENO, 1990. PAVIA, 2002]. 
Ahí, por tanto, en sus escritos, es donde podemos rastrear "lo que pretende" el músico (lo que busca, lo que le inquieta o interesa) y otra cosa bien distinta será, evidentemente, que consiga o no, en la prácti$\mathrm{ca}^{35}$, lo que plantea.

En definitiva, resulta algo obvio (es un hecho, a pesar de que a menudo todavía algunos intérpretes puedan pasarlo por alto), que estos escritos y tratados teóricos son hoy en día de enorme ayuda, cuando no imprescindibles, para tratar de entender los procesos, las búsquedas, intereses, etc. de los músicos del pasado, bien entendido que, habremos de ser conscientes de que, el hecho de intentar aproximarnos al pensamiento del compositor, podrá generar asimismo una cierta distorsión...

Por otra parte, algunos escritos sobre música de los siglos XVII y XVIII tratarán no sólo de la propia esencia de la música (de su concepción, filosofía, reglas de composición y teoría...), sino que abordarán también toda una serie de cuestiones relacionadas con la ejecución e interpretación. Nos ofrecen así una serie de pistas, coetáneas (¿fidedignas?) ${ }^{36}$, que resultan de gran ayuda a la hora de acercarse a la recuperación -práctica- de la música de aquella época en la actualidad.

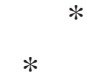

De lo que en definitiva se trata, en el itinerario que a lo largo de este artículo se ha pretendido recorrer, es de aproximarnos a los problemas de la propia ejecución detectados con la puesta en práctica de la música-escrita, ante los cuales el intérprete ha de optar "forzosamente", por tomar, en cada caso, una decisión entre las muchas posibles. Llegados a este punto, y sea cual sea la propuesta final escogida, conviene, evidentemente, considerar siempre dicha opción (como cúmulo de las diversas decisiones adoptadas) a la luz del estudio de las propias fuentes, así como de la documentación que las pueda contextualizar (informaciones sobre el compositor, sobre la composición y las actuaciones de la capilla musical catedralicia en la época, datos extraidos de los tratados teóricos del momento...), instrumentos conservados, etc.

De hecho, el trabajo a realizar tendría una doble vertiente, que necesariamente habría de hilar la labor musicológica y la musical:

35 Hay que tener en cuenta que el mismo músico que ha escrito un tratado, puede aplicar o no su pensamiento a la práctica musical, por muy distintos motivos o intereses. Además, la calidad que éste alcance en cada una de sus facetas (como teórico, y como práctico), así como el grado de dedicación e interés que destine a cada una de las mismas, puede ser muy diferente. Así por ejemplo, puede involucrarse más con una de las dos facetas que con la otra, e incluso puede hacerlo mejor o peor, según los casos y las circunstancias, e incluso puede evolucionar de manera diferente en uno y otro ámbito...

36 Dichas pistas o indicaciones referentes a la ejecución práctica de la música en la época que nos transmiten las fuentes teórico-musicales, han de leerse hoy día con espíritu crítico. Así por ejemplo, el hecho de que se prescriba por escrito que no se obre de una determinada manera (por ejemplo, que no se introduzca la música de comedias en los templos), puede significar -y esto, no pocas veces- que, precisamente, era bastante habitual en la época la práctica de lo que ahí se prohíbe, y que, por tanto, se quería atajar. Esta reflexión nos podría llevar al siguiente dilema: el músico práctico actual, al enfrentarse a tales casos, ¿debería cumplir con lo que se prohibía?, ¿o incumplirlo -y por tanto, hacer lo que parece que se hacía en la práctica-? ... 
1) En primer lugar, correspondería más bien al ámbito del musicólogo o investigador, proceder a realizar una transcripción (en aquellos casos en que la notación así lo requiera) o una edición crítica: una propuesta, para el estudio, y - lo que es más importante - para la ejecución práctica ${ }^{37}$.

2) En segundo lugar, la propia interpretación práctica vendría a ser, valga la redundancia, una propuesta de la propuesta editada, dado que casi cada paso conducente a la ejecución supone ir tomando decisiones, de entre las varias posibles: en cuanto al diapasón, el temperamento, los instrumentos escogidos para desempeñar la función del acompañamiento y el modo de realización del continuo, la ornamentación, etc.

Sobre los diversos dilemas con los que el músico práctico habrá de enfrentarse a la hora de abordar su interpretación propiamente dicha, ofrecemos a continuación algunas pistas de utilidad $^{38}$ :

- El diapasón. Antes de la adopción generalizada de un "La" de referencia (a 440 hercios), no se disponía de un mismo diapasón de aplicación general, lo que causaba la existencia de diferentes sonidos (alturas) de "referencia" según lugares y épocas. Prueba de ello es el hecho de que se hayan conservado instrumentos que varían, en este aspecto, incluso en una distancia superior a un tono; en este sentido, los ejemplos que nos ofrece Daniel Blanxart, entre otros, nos dan idea de las grandes variaciones en cuanto al diapasón, tanto en el tiempo como en el espacio, así como de lo mucho que todavía nos queda por conocer al respecto ${ }^{39}$ : en 1688, el La 3 del órgano de San Jacobo de Hamburgo estaba a 489 $\mathrm{Hz}$, mientras que en 1713 el de la Catedral de Estrasburgo daba 392; a mediados del siglo XVIII, se tiene noticia en Inglaterra de un órgano a 395, y otro a 522 ( una diferencia aproximada de dos tonos y medio!); mientras que en 1810, el órgano mayor de Notre-Dame de París estaba a 405 Hz. Por citar algunos casos más cercanos al ámbito hispánico: en el órgano de la iglesia parroquial de Nuestra Señora de la Asunción, de Longares (Zaragoza) ${ }^{40}$, de finales del siglo XVII, la frecuencia del caño "A" es de aproximadamente $415 \mathrm{~Hz}$, lo mismo que sucede con otros órganos de la misma época conservados ${ }^{41}$.

37 Así por ejemplo, suponen propuestas las decisiones tomadas por el editor en cuanto a la aplicación del texto a las voces cuando éste no se explicita claramente en la fuente; o la sugerencia de voces o instrumentos concretos cuando éstos no se especifican, aunque pueden colegirse por otros cauces; o la reconstrucción de la música en los casos en que ésta ha sido imprescindible por faltar en el manuscrito; o la sugerencia de la "semitonía subintellecta"; etc.

38 Dada la brevedad requerida para el presente escrito, resulta imposible abordar de manera exhaustiva todas las cuestiones que han de resolverse ante la ejecución de obras de este tipo, así como realizar una reflexión de los dilemas aquí planteados, con toda la profundidad que sería necesario. De este modo, se propone que las cuestiones aquí tratadas se tomen como punto de partida para posteriores estudios sobre el tema.

39 BLANXART, 1963: 109-130. Según este autor, a partir de 1700 hubo una marcada tendencia a ir subiendo la altura de la nota "La 3" (según el índice acústico franco-belga), que se correspondía con unos $400 \mathrm{~Hz}$ a principios del siglo XVIII. Para mediados del siglo XIX parece ser que este "La 3" alcanzaría ya los $450 \mathrm{~Hz}$ como promedio, hasta que, en el año 1859, una comisión nombrada a tal efecto en París, determinó de modo oficial el "La" a 435 Hz (España lo adoptaría oficialmente por decreto en 1879). Sin embargo, no sería hasta 1939 cuando, en virtud de la adopción entonces realizada por la International Federation of Standardizing Associations, se fijó el actualmente más extendido "La" a $440 \mathrm{~Hz}$. En consecuencia, todavía hoy podemos escuchar algunas grabaciones antiguas realizadas con órganos históricos del Norte de Europa en las que, suponiendo que las obras se hayan ejecutado en su tonalidad original, suenan medio tono e incluso un tono más bajo que el "La" actualmente adoptado a nivel internacional $(440 \mathrm{~Hz})$.

40 Este instrumento, construido entre 1669 y 1699 por Josef Mañeru (organero de la villa navarra de Lerín), parece que nunca sufrió transformaciones en lo que respecta al diapasón, y prueba de ello son las tapas soldadas de los caños cuya armonización es enteramente original. [Véase: -FREYTAG, 1985].

41 Entre los cuales están los órganos zaragozanos de: la iglesia parroquial de San Miguel Arcángel de Trasobares; la iglesia parroquial de Nuestra Señora de la Asunción, de Almonacid de la Sierra; la iglesia de la Virgen del Cristo, de Tobed (Zaragoza); 
Incluso el órgano más tardío de la iglesia de San Severo (Barcelona) -de la segunda mitad del siglo XVIII-, presenta un diapasón para la nota $L a$ asimismo en torno a los $415 \mathrm{~Hz}$, diapasón que resulta ser, hoy en día, el más extendido entre los profesionales para la interpretación de música de la primera mitad del siglo XVIII ${ }^{42}$.

- El temperamento. Para la primera mitad del siglo XVIII, no se contaba con un temperamento de aplicación generalizada para toda Europa, dado que éste podía variar ligeramente de un lugar a otro (incluso a veces entre emplazamientos muy cercanos), como tampoco existía una norma al respecto con carácter temporal: el temperamento utilizado podía variar con gran facilidad de un año para otro, o incluso podían solaparse o superponerse en el tiempo unos tipos de temperamentos con otros. Como dato de referencia internacional, debemos tener en cuenta que J. S. Bach escribe el primer tomo de $E l$ clave bien temperado en 1721. Entretanto en cambio, da la impresión de que los teóricos españoles de esta época, o bien no se interesan por el tema ${ }^{43}$, o bien no lo abordan explícictamente con la minuciosidad con que se hace en otros países, lo cual se hace patente, muy particularmente, en lo concerniente a aportar una solución al progresivo aumento del uso de las alteraciones, lo que complicaba, sobre todo, la afinación -por enarmonización- de las teclas "negras" 44 de los instrumentos de teclado ${ }^{45}$.

etc. Vid.: VALERO y RAINOLTER-WETTER, 1991. SAURA, 2001: 171-172 (“Diapasón”).

42 La relativamente "nueva" adopción de este diapasón para el repertorio y literatura de "música antigua" (particularmente de la primera mitad del siglo XVIII) ha resultado favorecida, debido a la difusión de la idea de que el diapasón más utilizado en la época pudo haber estado alrededor del $L a$ a $415 \mathrm{~Hz}$ así como, sobre todo, debido a que muchos de los instrumentos "históricos" construidos desde mediados del siglo XX (realizados a partir de planos o directamente de instrumentos conservados en museos o colecciones, ...) han adoptado dicha referencia, para la fabricación, con vistas a cubrir la necesidad de los actuales músicos que suelen utilizar dichos instrumentos de manera "concertada" (de modo que, lo que respondería a una "¿necesidad?" de nuestra época actual, sería seguramente algo que iría "en contra de" lo que pudo haber sido, valga la redundancia, la "realidad práctica" de la mencionada época pasada). Otros factores que han podido intervenir en la adopción del $L a$ a $415 \mathrm{~Hz}$. para la música, al menos, de la primera mitad del siglo XVIII, han podido ser los propios estudios realizados al respecto por los actuales constructores de "instrumentos de época" (se habla en este sentido hoy día de "copias fidedignas", de "reproducciones de época"...), los cuales, si bien se han desarrollado a menudo no de manera industrial sino siguiendo la tradición de los gremios y manufacturas artesanales han evolucionado, a grandes rasgos, no de una manera sistemática (p.ej., reproduciendo el máximo posible de instrumentos para tecla de un determinado período histórico en un área geográfica concreta), sino a partir de las eventuales reproducciones que han ido surgiendo o que se han ido encargando, en función de las peticiones de los propios instrumentistas actuales. Todo ello ha conducido a una "moda" entre los músicos especializados, en el sentido de que éstos han asumido dicho diapasón a 415 Hz.: el músico compra su instrumento así afinado, se conjunta con otros colegas que se encuentran en las mismas circunstancias, y todos, obrando de dicho modo (siguiendo "la convención"), cuentan con la ventaja de que no han de preocuparse más de este aspecto. Podría decirse invirtiendo el concepto, que obrar de otro modo (proponiendo otro diapasón que no fuese ése, o el actual a 440), podría ser visto como una "rareza", dado que si no se opta por una solución en este punto de partida del diapasón, el intérprete no puede conjuntarse de modo que no se puede continuar, ... Queda claro pues, que este asunto es fundamental y, seguramente, como ya queda dicho, los músicos de épocas pasadas debieron enfrentarse sin duda a este mismo tipo de problemas, por cuanto en el momento de "sonar juntos", debían adoptar unas medidas de partida, entre las que tomar como punto de referencia un mismo sonido para todos, sería lo primero. [Véase: HAYNES, 2001: 793-802. Y para ámbito hispánico: BORRÀS, 2009].

43 Eso no quiere decir, no obstante, que no se aborde el tema en absoluto; véanse por ejemplo los siguientes trabajos: BERNAL, 1999: 157-174. [Este trabajo parte de unas indicaciones al respecto de fray Pablo Nassarre e intenta ofrecer una solución a los problemas surgidos al aplicar dichas indicaciones del teórico]. También encontramos ciertas indicaciones en: MARTíN Y COLL, 1709b ( $c f r$. especialmente el apéndice "Modo de templar el órgano, clavicordio y arpa", pp. 407-410). Así como, ya en la segunda mitad del siglo XVIII: SOLER, 1762. [Véase también: SAURA, 2001: 459 (“Templar”). Y LINDLEY, 2001: 248-268].

44 Téngase presente que nos referimos, en este caso, a las actuales teclas negras (esto es, las notas alteradas o "cromáticas"), dado que en los instrumentos del siglo XVIII, a menudo los teclados se construían con colores invertidos a los que hoy estamos acostumbrados.

45 Hemos de tener en cuenta al respecto diferentes cuestiones: 1) Bach plantea su Clave bien temperado como una muestra de las grandes posibilidades (para todas las tonalidades) que aporta el sistema de temperamento igual; pero eso no implica que ya para entonces se tratase de un sistema de aplicación generalizada, aunque síllegara a serlo en breve tiempo. 2) Los teóricos españo- 
Lo que sí parece claro, sin embargo, es que bien entrado el siglo XVIII y al igual que sucediera en el resto de Europa, los músicos de la península tenderían a acercarse progresivamente (dado el aumento paulatino en el empleo de alteraciones y, a partir de ahí, la cada vez mayor incomodidad de diferenciar una nota sostenida de su enharmónica bemol, y aún más en determinados instrumentos -v.g., el órgano-), al temperamento igual. De este modo, se tiene constancia, por el libro de Pablo Minguet e Yrol, Reglas y advertencias generales que enseñan el modo de tañer todos los instrumentos...46, de que en el teclado del clave y del órgano (de 51 teclas) las notas negras servían tanto para los sostenidos como para los bemoles, de donde podría inferirse que (si y sólo si tal afirmación fuera de aplicación para "todas" las dichas teclas negras), al menos desde mediados del siglo XVIII, los músicos de ámbito hispánico y sus instrumentos, aplicaban ya el temperamento igual.

- En cuanto a la elección de los instrumentos que realizan el acompañamiento en la interpretación, dada la habitual carencia de indicaciones al respecto en las fuentes, hemos de recurrir a la valiosa información que nos ofrecen los escritos teóricos del momento. Entre ellos, quizá uno de los más completos y representativos sea el Mapa Armónico, en el cual F. Valls señala, a la hora de enumerar los instrumentos encargados de la realización del continuo: como polifónicos, al órgano, el clavicémbalo, la espineta, el arpa, el archilaúd, la guitarra, etc.; y entre los monódicos, al bajón, el fagot y el violón ${ }^{47}$. Por su parte, P. Rabassa señala como instrumentos encargados de hacer el acompañamiento, el órgano, el arpa, el archilaúd y el fagot o bajón dulce, aunque también cita, refiriéndose a los instrumentos en general, el bajón, bajo de violón y contrabajo de violón ${ }^{48}$. Pablo Nassarre, por su parte, recalca la importancia del arpa como instrumento de la realización del continuo, siendo para él "uno de los instrumentos eclesiásticos, pues en España está tan introducida en las iglesias, para acompañar las capillas, que es poco menos que el órgano"49.

- Mucha más información nos ofrecen los citados tratados teóricos en cuanto al modo de la realización, propiamente dicha, del continuo $0^{50}$. Por poner algunos ejemplos: José de Torres y Martínez Bra-

les pudieron no haberse interesado por el tema, porque se trataba de una cuestión técnica que, como tantas otras, se solucionaba en la práctica antes de la ejecución, concertándose de forma oral entre los diferentes ejecutantes; o porque, como señalan algunos tratadistas hispánicos (G. Sanz, F. Valls...), la proliferación de alteraciones en otros ambientes foráneos (además a menudo, promovidos por agentes civiles o profanos), era ajena o extraña al ámbito hispánico (mayoritariamente católico), mucho más sujeto por la tradición religiosa y por una teoría musical supeditada a la misma. 3) El hecho de usar menos alteraciones en ámbito hispánico pudo traer consigo que el problema de tocar dos notas con una misma tecla negra llegara mucho más tarde en el tiempo. 4) La práctica del transporte en ámbito hispánico era de extensión generalizada y frecuente, de suerte que el hecho de que una fuente documental se anotara con múltiples alteraciones, no implicaba necesariamente que debiera de interpretarse así. 5) Por otro lado, ya fray Juan Bermudo (en su Declaración de instrumentos musicales. Osuna, Juan de León, 1555), hablaba de las diferentes posibilidades de transporte, enarmonización, y problemas con las teclas negras (dado que algunas alteraciones eran imposibles para su época)... Por tanto, podríamos concluir que el problema sí que se conocía en España, pero que muy posiblemente no era necesario de resolver por escrito - al menos, no con carácter imperioso - en la práctica (dado que se solventaría con otras múltiples posibilidades como las apuntadas), lo cual no se suscitaría sino hasta ya muy entrado el siglo XVIII, tiempo que coincide, curiosamente, con la aparición, cada vez más generalizada, de nuevos instrumentos de teclado como el pianoforte.

46 MINGUET, 1752-1754. Véase también: BORDAS, 2000: 201-217.

47 PAVIA, 2002: 250. Sobre este tema véase también: MARTÍN MORENO, 1976-1977: 157-194.

48 BONASTRE, CLIMENT y MARTÍN MORENO, 1990: 505-508. Sobre este tema véase también: ISUSI, 1997: $401-416$.

49 NASSARRE, 1724: 331. En este sentido, cabe señalar que es abundante la documentación catedralicia hispánica de la época que recalca la importancia de este instrumento (el arpa) con función de acompañamiento en las capillas de música.

50 Véase al respecto: GONZÁLEZ MARÍN, 1991. 
vo, en sus Reglas generales de acompañar, en organo, clavicordio, y harpa... ${ }^{51}$ nos ofrece algunas advertencias, a nuestro parecer especialmente interesantes, al respecto, como:

"Que procure llevar las manos vnidas, para que con esso no vayan las voces muy distantes del baxo $[\ldots] "$

"Que sobre todas las notas, ò puntos, es de obligacion poner quatro voces, o à lo menos tres, incluyendo en ellas el baxo [...]"52,

"Que el acompañante se ha de hacer cargo de las partes cantantes que acompaña, para cuydar, si se adelantan, adelantarse, ò al contrario, atrassarse, por ser esta obligacion precisa del que acompaña";

"Que al finalizar ha de esperar à que el Cantor cayga à la Clausula, para que no fenezca el acompañante antes que la voz $[\ldots]$ "..

"Que cuando se acompaña no se ha de glossar, ni con la mano diestra, ni siniestra, sino es que sea con mucha discrecion $[\ldots]$...53;

"Que aunque conozca el parage por donde camina la voz, no la ha de ir tocando con la mano diestra $[\ldots]^{54}$, etc.

También en este sentido nos ofrece algunas reglas o recomendaciones Francisco Valls, al indicar por ejemplo, en cuanto a la forma de realización del acompañamiento continuo de los instrumentos polifónicos, que en las partes fuertes del compás y en movimientos disjuntos o saltos, se deben colocar acordes consonantes, aconsejando a su vez que se cifre dicha parte con detalle ${ }^{55}$, muy posiblemente para evitar errores en su realización.

- En lo que respecta a la fabricación de los instrumentos más apropiados para la interpretación de la música barroca hispánica de esta época -dado que la mayoría de las veces el intérprete no dispone de originales históricos sino más bien de réplicas actuales de instrumentos de época conservados en diferentes museos y/o colecciones de Europa- podría parecer, en principio, que, al menos, éstos deberían ser "copiados" a partir de modelos autóctonos. Sin embargo, este aconsejable requisito para la interpretación de fuentes del siglo XVII, no lo es tanto para las obras posteriores, en tanto que

51 TORRES, [1702 y] 1736.

52 TORRES, op. cit., Capítulo I del Tratado Segundo, p. 19. Otro buen consejo de Torres en este sentido es: "Que la execucion del acompañamiento, pertenece à la mano siniestra, formando con dicha mano unas veces octava, y otras quinta, segun la ocasion, y el lugar, para que con esso suene mas armonioso. Excetuasse, quando el acompañamiento tañe imitacion, ò fuga, que entonces se ha de tañer llano, como està escrito, sin añadir, ni quitar, porque de lo contrario, lo que se sigue es, perder el oido, el gusto de la imitacion [...]".

53 TORRES, op. cit., Capítulo XI del Tratado Tercero, pp. 94-95. En este punto coincidirán J. de Torres y F. Valls en tanto que este último, especialmente en lo que se refiere a la ejecución del bajo y el acompañamiento, recomienda fidelidad a la partitura (está en contra de las glosas), aconsejando sólo los adornos, sobre todo en las obras a pocas voces, y curiosamente, a imitación de los italianos y los franceses.

54 TORRES, íbid. En esta última recomendación coincidirá también F. Valls, en cuanto indica que, en los casos en que el acompañamiento lo es de sólo una o dos voces, no se ha de duplicar la melodía que se acompaña, sino que conviene añadir una tercera voz "que cante graciosamente" [PAVIA, 2002: 251]. Otros de los consejos que Torres nos ofrece aquí son: "Que se ha de dar à las notas su valor propio, guardando los puntillos, y pausas que se hallaren, por ser obligacion el executar lo que està en el papel sin añadir, ni quitar, [...]"; o "Que procure no sobresalir con el instrumento quando acompañare à vna, o dos voces, sino que atendiendo al metal de ellas se vaya ciñendo, poniendo pocas voces, y essa baxas, y tambien apagandolas, y en otras ocasiones, dando muchas consonancias para que sobresalga el instrumento por ser muchas las voces, ò por el metal de ellas, ò por pedirlo el afecto de la letra [...]".

55 PAVIA, 2002: 251. 
ya desde los primeros años del siglo XVIII, la música hispánica - y con ella sus instrumentos - se debatía entre sus recursos más tradicionales y las propuestas extranjeras más innovadoras ${ }^{56}$. Es más, en el transcurso de unos pocos años, el fenómeno extranjerizante afectó a los instrumentos de que disponan los músicos, por cuanto: se importarán -apertura del comercio- instrumentos de otros lugares, sobre todo de Europa (Francia e Italia); los propios músicos extranjeros traerán consigo sus propios instrumentos construidos en sus lugares de origen; se empiezan a asentar fabricantes extranjeros, sobre todo franceses e italianos, en los principales centros de producción (Madrid y Barcelona); como consecuencia de dicho asentamiento de constructores extranjeros en España y de la moda del momento, los mismos constructores españoles adoptarán técnicas de construcción extranjeras, como las italianas -lo que se ve por los instrumentos conservados a partir de la segunda década del siglo XVIII- principalmente en los instrumentos de cuerda frotada. Sólo el caso concreto del arpa, supondrá una excepción en este sentido, en tanto que tendrá unas características propias, que la diferenciará de las extranjeras: el arpa hispánica (cromática) de dos órdenes ${ }^{57}$.

- Encontramos mucha más información -en la que, por razones de espacio, en esta ocasión no nos podemos detener- al estudiar los escritos, la documentación y las fuentes de la época, respecto al modo de ejecución (en la que se suele distinguir entre las voces ${ }^{58}$ y los instrumentos ${ }^{59}$ ), considera-

56 De este modo, si bien es cierto que la mayoría de los instrumentos utilizados en el ámbito eclesiástico durante el siglo XVII eran de procedencia nacional -siendo construidos por los mismos gremios españoles-, es más que probable que este panorama cambiase a partir de las dos últimas décadas del mismo siglo, y más aún cuando, con la llegada de la nueva dinastía de los Borbones y el reinado de Felipe V, se iniciaría una importante reforma administrativa que abriría la economía a nuevos planteamientos comerciales y que afectaría, directamente, a los gremios de construcción de instrumentos. Como bien dice C. Bordas, los constructores de instrumentos -como oficio manual y por tanto del estrato social más bajo- sufrieron directamente las consecuencias de las nuevas reglamentaciones establecidas por Felipe V, quien, además, aplicó dicha reforma en su propia casa y capilla, extinguiendo los sueldos que recibían los fabricantes de instrumentos de cuerda y viento, de modo que, al igual que los restantes "oficiales de manos" cobrarían, a partir de ese momento, sólo por las obras realizadas. [Cfr.: BORDAS, 2000: 201-217].

57 El arpa barroca de dos órdenes hispánica (primera, "orden diatónica"; segunda, "orden cromática"; denominación tomada de los instrumentos de teclado) consta de dos filas ("órdenes") de cuerdas. La descripción histórica más completa de la misma - desde el punto de vista de su construcción- que se ha podido localizar, es la de fray P. Nassarre [NASSARRE, $1724: 458$ y ss.], quien nos dice que el arpa excede a los demás instrumentos de cuerdas de tripa por su mayor volumen sonoro, a lo que añade su amplia tesitura (la misma que los instrumentos de teclado), siendo por todo ello muy apreciada para acompañar las capillas de música. Parece ser que hacia finales del siglo XVII o, como mucho, principios del XVIII, todas las arpas de dos órdenes hispánicas eran cromáticas completas. [Sobre el arpa hispánica de dos órdenes véase también: BORDAS, 1989: 85-117; y BORDAS, 1987: 148-163. CALVO-MANZANO, 1992].

58 En este sentido nos dice, por ejemplo P. Nassarre, refiriéndose a los criterios que deberían tenerse en cuenta a la hora de seleccionar a los cantantes que "El modo de proceder en los examenes de Musicos de voz, se reduce tan solamente à hazer experiencia si son diestros en el cantar, y à atender que qualidades tiene la voz [...] [y] en el modo de cantar, en la pronunciacion, y en el modo de glossar los transitos. En el modo de cantar, si es ayroso: porque ay algunos que cantan con tanto decaymiento de la voz, que no dàn gusto con lo que cantan. Conviene, que tengan buena pronunciacion, para que se entienda bien la letra: para lo qual importa mucho que sean buenos lectores. En cuanto al glossar los transitos, conviene, que sean glossitas graciosas, que dicho modo de cantar causa deleyte, y gusto", así como que "Las qualidades de la voz de qualquier especie que fuere, importa que sean las siguientes. El cuerpo de la voz, bastante; que sea larga, subiendo por la parte aguda, y baxando por la grave todo lo que fuere necessario para la parte que huviere de cantar, ha de ser la voz clara, e igual [...]". [NASSARRE, 1723: 491-492]. A su vez, también señala como los defectos más corrientes en la emisión vocal, la voz nasal y la mala articulación, criticando duramente, sobre todo, los vibratos exagerados de aquellas "voces con defecto tan notable, que causa pena al oyrlas, y es porque estan tremolando sin ajustarse al tono fijo y parece que tiemblan cuando cantan" [NASSARRE, 1724: 51].

59 Al referirse a los defectos de los cantantes e instrumentistas en cuanto a la interpretación, F. Valls considera que "El primero, y mas principal, es, cantar en el Templo, como en el teatro con blandura afeminada, quiebros amatorios contra las reglas de la decencia [...]", lo que, según dice, suele ocurrir en las composiciones en lengua vulgar, proponiendo para remediar "este gravissimo daño", que se cante "con espiritu varonil, acompañando aquella Musica con los afectos correspondientes á la letra, mas 
ciones "estéticas" (referentes, sobre todo, a la expresión de los afectos), la colocación de voces e instrumentos ${ }^{60}$, etc. que esperamos poder tratar en próximos escritos.

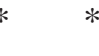

\section{A MODO DE CONCLUSIÓN:}

Como se ha visto, no sólo el estudio sino también la interpretación de fuentes de la primera mitad del siglo XVIII puede y ha de realizarse con un rigor que ha de conjugarse con los determinantes de los tiempos presentes. Ciertamente, como se ha visto, son varios los escritos y documentos del siglo XVIII que tratan temas relacionados con la ejecución musical: los tratados teóricos, por ejemplo, contienen reglas generales y exponen los preceptos esenciales a los que "en teoría” debía ceñirse el músico de la época ${ }^{61}$ y, por lo tanto, también el ejecutante actual que pretenda interpretar dicha música según los cánones históricos.

Ya hemos comentado también cómo (dejando bien sentada la importancia de realizar un buen estudio de la música anotada en las fuentes que se van a ejecutar, y de conocer el pensamiento teórico del momento histórico que se trabaje), importa mucho también, si se pretende una aproximación "bien informada" a la música del pasado, que la ejecución de dicha música cuente, a cada ocasión, con un fundamental componente de creación artística, pues, de hecho, así es como debió concebirse en origen (no se anotaba la semitonia subintellecta, había un lugar para la glosa o la ornamentación, el ejecutante concreto podía realizar determinadas intervenciones no escritas sobre la composición que "interpretaba", etc.). Por lo tanto, si las músicas pasadas respondieron en origen a ejecuciones "abiertas" a diferentes opciones o posibilidades, y distintas cada vez que sonaban, una reconstrucción de aquellas músicas desde la actualidad, no debería renunciar a ese factor de momentaneidad (se hacía esa música, "asî" -de esa manera-, en ese momento y ese lugar concretos, pero ya nunca más podría suceder del mismo modo): recordemos que ésa es, precisamente, la esencia universal de toda música, para todo tiempo y lugar (nunca se puede ejecutar una misma obra exactamente del mismo modo dos veces, aunque se quiera).

siempre con el cuidado, que en lugar tan sagrado [el templo] es permitida la Musica, para excitar la devocion del auditorio, y para vna decente recreacion de el sentido." [PAVIA, 2002: 515]. Por su parte, Nassarre aconseja a los instrumentistas "la igualdad en el herir las cuerdas, ò teclas de el Instrumento; porque de no herirse con igualdad, se siguen dos inconvenientes, no poco notables. El uno, que los sonidos que se hieren con menos violencia, ordinariamente se acelera mas el tiempo en ellos, y se falta al justo valor de las figuras, y consiguientemente à la igualdad de el compàs. El segundo, que quitan grados de armonia, quando los sonidos no tienen igual cuerpo [...]" [NASSARRE, 1723: 431]. Etc.

60 En este aspecto, Valls aconseja colocar "las vozes cercanas á los acompañamientos. Los instrumentos de Violines, y Oboesses en ala detràs de los acompañamientos, y vozes: y los baxos de violines, o Fagottos, que estén juntos á los acompañamientos, á las espaldas de ellos, que de esta manera irán mas vnidos; las vozes resaltaràn mas, y la Musica se ajustará mejor [...]” [PAVIA, 2002: 514].

61 Aunque, por otra parte, el hecho de prescribir unas reglas no supone, en absoluto, su cumplimiento, sino que en ocasiones puede significar lo contrario; en esa línea, no se prescribiría necesariamente aquello que fuera común y usual sino, normalmente, aquello que conviniera dejar por escrito para recordar como norma. Y siguiendo con el razonamiento, ¿qué debería hoy hacer el ejecutante?, ¿cumplir la norma que establecía la teoría, o incumplirla, como posiblemente sucediera en la práctica? ... 
Obviamente, a todo ello todavía habría que sumar, por un lado, que nuestra manera de pensar, sentir y concebir la vida, es muy distinta de la del hombre del siglo XVIII, y por otro lado, que las condiciones sonoras de los instrumentos y las voces de aquella época eran, aunque intentemos aproximarnos a ellas, distintas de las actuales (las reconstrucciones o copias modernas de instrumentos antiguos, pese a un sinfín de experimentos y cálculos minuciosos, jamás conseguirán proporcionarnos una reproducción e imagen absolutamente fieles de cualidades del sonido de entonces...). De este modo, el intérprete actual ha de desempeñar necesariamente una función de "intercesor", de mediador, entre el ayer y el hoy, conjugando las enseñanzas de los escritos de época con la realidad del siglo XXI ${ }^{62}$.

De hecho, la realidad de nuestra propia época es la que nos influye, de uno u otro modo, ante el rescate (y a un rescate concreto) de esta música del pasado ${ }^{63}$. En este sentido, puede resultar de interés detectar algunos factores que hacen que nuestro "rescate" actual de la música del período barroco esté sometido a importantes condicionantes, como, por mencionar algunos ejemplos: 1.- En cuanto al número y tipo de intervinientes, es fácil montar programas con pocos efectivos, pero complicado montar un programa, por ejemplo, policoral, o que requiera de una gran agrupación con variedad de instrumentos musicales ${ }^{64} ; 2$.- El gusto o aceptación de una audiencia "acostumbrada" a un tipo de repertorio concreto (que oye por tanto ese mismo repertorio sin esfuerzo, pero que le cuesta aprehender otro tipo de literatura más infrecuente, y por tanto hasta cierto punto considerada como "árida"), de modo que resulta a menudo más fácil montar conciertos solísticos, sonatas, incluso cantatas, que ofrecer programas de carácter litúrgico, fuera de los grandes nombres de compositores del "Siglo de Oro" español; 3.- Las características de los espacios de que se dispone en la actualidad resultan, asimismo, un condicionante más: los ciclos de conciertos más especializados cuentan con grandes salas (del tipo auditorios), adecuadas hasta cierto punto para un tipo de literatura sinfónica y de concierto solista que se ajusta bien a la literatura musical que va desde finales del siglo XVIII hasta el siglo XXI; los conciertos programados en iglesias, en cambio, por meras cuestiones de aforo y de carácter de la sala (espacio religioso), condicionan un público menor que en el primer caso, un repertorio que no puede salirse del "decoro", además de una acústica concreta, etc. etc. ${ }^{65}$; 4.- Quien paga la música es, hoy en día, quien decide qué, cuándo y cómo se programa, ya sea este

62 El principal y más frecuente desajuste entre la realidad musical del momento y las interpretaciones actuales, suele consistir en que, ante la duda, o la carencia de información, se peca, no pocas veces, de un enriquecimiento en la ejecución, en cuanto a la cantidad de instrumentos del acompañamiento, la calidad de los cantantes e instrumentistas, e incluso la elección de los propios instrumentos, la técnica, etc.

63 Algunas de las ideas expuestas hasta aquí pueden verse en algunas de nuestras propias producciones, tanto en edición impresa [GONZÁLEZ MARÍN, 1991: 45-52; GONZÁLEZ MARÍN, 1993: 63-102; ROSA, 2004: 85-114; ROSA, 2006: 155-165; EZQUERRO, GONZÁLEZ-MARÍN y GONZÁLEZ-VALLE, 2008b; ROSA, 2008; EZQUERRO et alii, 2009; GONZÁLEZ MARÍN, 2010: 81-117; ARTIGAS et alii, 2010; EZQUERRO, 2011; ROSA, 2011: 471-494; EZQUERRO, en prensa], como discográfica en CD [ROSA, 2006a; ROSA, 2006b; ROSA, 2008; GONZÁLEZ MARÍN, 2009; ROSA, 2010; GONZÁLEZ MARÍN, 2010; ROSA, 2012].

64 Resulta evidente que la participación de un número elevado de ejecutantes comporta, hoy, mayores costes económicos, y de gestión, lo que condiciona asimismo, una mayor dificultad en las contrataciones, y por tanto, reduce el porcentaje de ejecución de este tipo de repertorio, haciendo que su presencia actual en las programaciones no sea representativa de la realidad pasada, cuando ese tipo de música (policoral, con agrupaciones de ministriles, etc.) era, precisamente, el más interpretado.

65 Asimismo, el espacio utilizado para una actuación musical, puede arrastrar a un tipo de audiencia u otra, generando así públicos y "costumbres" diferenciados. Por otro lado, todavía resulta complicado determinar hoy en día cuál podría ser el lugar más apropiado para (fuera de los grandes teatros, en la mayoría de los casos con un aforo e incluso con un escenario excesivos 
pagador o "mecenas" una persona física o una institución pública o privada (un político, un banco o caja de ahorros, un ayuntamiento o una asociación filarmónica...), salvo que se delegue en un programador musical que "acuerde" con el financiador las líneas básicas a seguir. En este último caso, las programaciones suelen depender de las modas y, en general, de la ley de la oferta y la demanda dentro de unos cauces, generalmente, restringidos y poco abiertos a innovaciones o apuestas arriesgadas o que se salgan de la tónica habitual. Con tales premisas, el criterio para la elaboración de las programaciones depende a menudo de personas no siempre lo suficientemente formadas para defender adecuadamente una recuperación de la música histórica que responda, no sólo a la búsqueda del espectáculo, sino más bien a un equilibrio entre la creatividad y la investigación.

Por otro lado, en un tiempo como el actual, en el que la sociedad demanda cada vez con mayor fruición nuevos nombres de compositores que poder incluir en las programaciones, nuevas formas musicales, nuevas plantillas vocales e instrumentales, y en fin, toda suerte de "novedad" que pueda servir para dinamizar las tradicionalmente repetitivas programaciones de concierto, el rescate de nuevos materiales ha tendido por lo general a seguir al menos dos tendencias:

1.- Una cierta política de selección de materiales tendente a "picotear" entre la literatura disponible, según un criterio, bien "de costumbre" (se elegirían en este sentido nuevos títulos que no difirieran mucho de los ya asumidos o incorporados a la programación habitual: sería "más de lo mismo", aunque obras poco oídas), bien de ganarse el beneplácito del público: por ejemplo, inclusión eventual en los programas generales de algunas obras -aquí y allá-, o de bises, que buscan el aplauso fácil, bien porque evocan cuestiones de "nacionalismo" en el que se intenta involucrar a la audiencia, o bien por las propias características musicales de la obra en cuestión (con empleo de tonalidades mayores, orquestaciones abultadas, ritmos rápidos y bailables, melodías pegadizas...).

2.- Tampoco la política musicológica ha estado ajena a esta tendencia, dado que ha sido relativamente frecuente hasta día de hoy, el hecho de que, con vistas a suministrar materiales y repertorios para la práctica, se trabajaran catálogos de archivos y bibliotecas musicales según los intereses concretos (o lo que es peor, según sus inclinaciones músico-artísticas) de los musicólogos que los realizaron: así por ejemplo, se desechaban, hasta hace relativamente muy poco tiempo, de los catálogos publicados, aquellas obras consideradas musicalmente como demasiado cercanas en el tiempo. Es el caso de muchos archivos, cuyos catálogos no abordan el siglo XX, e incluso buena parte del XIX. De manera similar, apenas existen catálogos temáticos de compositores españoles, a la manera por ejemplo del BWV para J. S. Bach, obra de Wolfgang Schmieder, o del Köchel para Mozart, Ryom para Vivaldi, Kirpatrick para D. Scarlatti, etc. Tampoco existen apenas monografías actualizadas y medianamente rigurosas o científicamente fiables, que aborden algunas de las formas o géneros musicales más propiamente hispánicos, como por ejemplo

comparados con los del momento) interpretar madrigales burlescos, o tonadillas escénicas, así como "disponer" con facilidad de los lugares para los que esa música pudo haberse concebido (salones palaciegos de la nobleza, corrales de comedias, etc.). Y en el caso contario, también nos encontramos hoy en día con una cierta tendencia a interpretar cualquier tipo de repertorio en cualquier espacio, sea o no apropiado para la música programada: caso por ejemplo de conciertos de canto gregoriano en auditorios, o de versiones operísticas o teatrales en general ofrecidas en centros religiosos, etc. 
las dedicadas al villancico o los tonos, las primeras zarzuelas y comedias armónicas, las cantadas, tonadillas, cuatros... (e incluso las formas o géneros no propiamente hispánicos, pero que cuentan con características propias de adaptación a nuestro entorno, como las sonatas, misas, oratorios, lamentaciones...).

Frente a semejante panorama, obviamente han surgido iniciativas muy loables, aunque a menudo individuales y realizadas desde puntos de vista locales o puntuales (focalizados en un compositor, una forma concreta en un lugar determinado, etc.), que han querido paliar la situación, aunque con desigual y en general escasa fortuna. Es más, a partir de la proliferación inconexa de este tipo de iniciativas, se ha constatado la urgencia y absoluta necesidad de perfilar algún tipo de proyecto coordinado sobre las investigaciones a realizar, que determinara las prioridades a seguir y estableciera una previsión de los trabajos, tanto en el tiempo como en el espacio, y tanto en lo más estrictamente musical, como en lo musicológico, tratando de coordinar las diferentes iniciativas particulares y conformando equipos de actuación. Así por ejemplo se pueden escuchar en España conciertos con la integral de las sonatas para piano de Mozart o Beethoven, ciclos con las cantatas completas de J. S. Bach, etc., pero es impensable todavía hoy escuchar (y que la Administración y los programadores “apuesten por") un proyecto para programar ciclos con la música, por ejemplo, de un único compositor español de los siglos XVI-XVIII, o de un único género en un único lugar, etc. etc., a excepción de casos muy aislados. Ni siquiera existen trabajos musicológicos que lo permitan.

Caso aparte es el de la "apropiación”, debida o indebida, de autores no nacidos en España, aunque considerados españoles por haber desarrollado buena parte de su actividad en nuestro país, como podría ser el caso de Domenico Scarlatti o Luigi Boccherini, sobre quienes ha recaído una mucho mayor atención. Pero no hay que perder de vista que incluso sus apellidos son foráneos, y su producción se halla dispersa por toda Europa, donde son conocidos como italianos, que, "como nota de color", desarrollaron parte de sus carreras profesionales en la "exótica" corte borbónica (francesa) española. Precisamente, de su música, lo más célebre, por lo "picoteado", es el repertorio más puramente "folclórico": los zapateados, seguidillas, fandangos y piezas por el estilo, que alimentan el tópico de españolidad castiza del siglo XVIII, madrileñoandaluza-italiano-internacional. Pero tampoco hay que perder de vista de que se trata de autores que llegan a España ya con una buena formación musical -adquirida fuera de España-, y que estuvieron activos en la corte de Madrid, y por tanto en un ambiente civil, "escogido" y con conexiones internacionales, bastante lejano a cuanto sucedía entre el común de las capillas y músicos españoles de su propia época, y por tanto, escasamente significativos/representativos. En esta línea, podría decirse que la política del picoteo se combina con la de selección de materiales que busca la audiencia y que valoran los propios profesionales como "buenos" (repertorio, géneros/formas musicales, compositores, etc. "de moda" y al uso en Europa), frente a dar a conocer todo lo que hay, o, al menos, un panorama diverso de los materiales disponibles que permita, a través de la audición, forjarse una idea, siquiera aproximada, de lo que pudo haber sido el "paisaje sonoro" de la época en la España del siglo XVIII. A pesar de evidentes avances en este sentido, estamos muy lejos todavía hoy en día del momento en que se puedan ofrecer, con naturalidad, programaciones de este tipo de repertorio, de obras conservadas en un único centro de producción, o dedicadas -con unidad de programa- en exclusiva a la obra de un único autor, a una forma musical concreta, etc. 
En definitiva, y siendo conscientes de que (a partir de una experiencia -como músicos e investigadores- familiarizada con las fuentes históricas musicales y documentales, así como con los tratados teórico-musicales de la época) lo hasta aquí planteado no pasa de ser más que unas pequeñas pinceladas entre las múltiples posibles, es decir, unos meros apuntes o pistas, para que el intérprete y el estudioso pueda hacerse una idea, acaso mejor, sobre aquello a lo que se está enfrentando a la hora de abordar este tipo de repertorio, el presente trabajo invita a la siguiente reflexión: sería preciso, hoy en día, re-plantearse determinadas aproximaciones actuales a la interpretación musical histórica, que se hacen, con cierta frecuencia, al calor de las exigencias del mercado y las modas, de suerte que se ofertan públicamente como "música antigua interpretada con criterios e instrumentos históricos", cuando, a menudo, prescinden o soslayan el imprescindible apego a las fuentes originales (documentación, tratados...), fijándose apenas, en exclusiva, en aspectos puramente prácticos y funcionales (lo que suena bien a nuestros oídos, lo que es vendible, lo que pretendidamente busca la audiencia...). Acaso, en este sentido, retomar la música antigua, tal y como pudo haber sido (con pocos recursos, menos técnica vocal e instrumental, unos instrumentos menos perfeccionados, etc.), pueda hoy en día no gustar, o gustar menos; y a ello todavía cabe añadir que tampoco hay que perder de vista que tenemos, de por medio, la poderosa influencia dejada sobre nosotros por el romanticismo (con grandes orquestas, virtuosismo y búsqueda de la perfección -en afinación, sonido, técnica, etc.-). Pero lo que sí es absolutamente indispensable, a nuestro juicio, es acercarse a esta música desde una constante inquietud por conocer el pasado, y por hacerlo "de primera mano", sin intermediarios, y muy especialmente, si el intérprete defiende que sus ejecuciones parten de la musicología, de la ciencia musical, y por tanto, pretende que respondan realmente a "lo que pudo haber sido" o a "cómo pudo haber sonado" dicha música.

Finalmente, y considerando que buena parte de las composiciones de ámbito hispánico de los siglos XVII y XVIII, se concebían originalmente para ser ejecutadas una sola vez (es decir, para un único momento o situación y lugar concretos, de modo que ya no se volvían a repetir), tampoco parecería lógico hoy en día rescatar aquella música para que vuelva a languidecer acto seguido; el objetivo, no es ése, sino que debería ser promover no un nuevo rescate de antiguallas ${ }^{66}$, sino promover, con la recuperación de nuevas fuentes, una nueva perspectiva de trabajo respecto a los materiales objecto de estudio: trabajar la documentación, y los tratados teóricos de la época, para ponerlos al servicio de una música nuevamente "viva" y no de museo, aunque realizada con rigor científico y unas mínimas necesarias garantías.

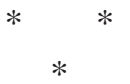

66 Hay que tener en cuenta que el contexto de ejecución ha cambiado; hoy, es bien distinto, y por otra parte, irrecuperable: el pasado se fue, y no volverá jamás, tal y como fue, por más que se pretenda lo contrario. De hecho, por ejemplo, ni hoy se interpretan ya las obras pasadas religiosas dentro del culto, ni el público acude ya hoy a escuchar esa música rescatada en un acto religioso, sino únicamente musical. 


\section{BIBLIOGRAFÍA}

AGUILERA DE HEREDIA, Sebastián, Canticum Beatissimae Virginis deiparae Mariae. Zaragoza, Pedro Cabarte, 1618.

ARANIÉS, Juan, Libro segundo de tonos y villancicos a una, dos, tres y cuatro voces, con la cifra de guitarra española a la usanza romana. Roma, Juan Bautista Robleti, 1624.

ARTIGAS PINA, Javier, et alii (eds.), Antonio de Cabezón (*1510c; †1566). Obras de música para tecla, arpa y vihuela (Madrid, Francisco Sánchez, 1578). Nueva edición crítica completa. 4 Vols. Zaragoza, CSIC-IFC, 2010.

BERNAL RIPOLL, Miguel, "El temperamento de Nassarre: Estudio matemático", en Revista de Musicología, 22/1 (Madrid, 1999), pp. 157-174.

BLANXART, Daniel, "Consecuencias que se deducen del estudio minucioso de las distintas gamas y de la evolución de la tesitura”, en Anuario Musical, 18 (Barcelona, 1963), pp. 109-130.

BONASTRE, Francesc, CLIMENT, José y MARTÍN MORENO, Antonio (eds.), Pere Rabassa: Guia para los principiantes, que dessean perfeycionarse en la compossicion de la mussica. Valencia?, 1724-1738. [Edición facsímil del manuscrito conservado en el archivo de música del Real Colegio del Corpus Christi de Valencia]. Bellaterra, Institut de Documentació i d'Investigació Musicològiques “Josep Ricart i Matas”, 1990.

BORDAS, Cristina, "The double harp in Spain from the 16th to the 18th centuries", en Early Music, 15/2 (Londres, 1987), pp. 148-163.

BORDAS, Cristina, “Origen y evolución del arpa de dos órdenes”, en Nassarre 5/2 (Zaragoza, 1989), pp. 85-117.

BORDAS, Cristina, “Tradición e innovación en los instrumentos musicales”, en La música en España en el siglo XVIII. [BOYD, Malcolm y CARRERAS, Juan José (eds.)]. Madrid, Cambridge University Press, 2000, pp. 201-217.

BORRÀS I ROCA, Josep, El baixò hispànic. Tesis doctoral, Barcelona, Universitat Autònoma de Barcelona, 2009.

BRICEÑO, Luis de, Metodo mui facilissimo para aprender a tañer la guitarra a lo español. París, Pierre Ballard, 1626.

CALVO-MANZANO, María Rosa, El arpa en el barroco español, 1. Madrid, Alpuerto, 1992.

CASTRO, Francisco José de, Trattenimenti Armonici Da Camera a tre, due violini, violoncello o cembalo. Bolonia, Pier Maria Monti, 1695.

CORREA DE ARAUXO, Francisco, Libro de tientos y discurso de música practica, y theorica de organo intitulado Facultad orgánica. Alcalá de Henares, Antonio Arnao, 1626.

DELGADO PARRA, Gustavo, "Los órganos históricos de la catedral de México", en Anuario Musical, 60 (Barcelona, 2005), pp. 41-70.

DELGADO PARRA, Gustavo, Un libro didáctico del siglo XVIII para la enseñanza de la composición: el " $\mathrm{Li}$ bro que contiene onze partidos” para órgano de Joseph de Torres en la colección “Jesús Sánchez Garza” del CENIDIM (México, D.F.). Tesis doctoral. Valencia, Universidad Politécnica de Valencia, 2007. 
DURÁN, Domingo Marcos, Lux bella. Sevilla, Paulus de Colonia, Johannes Pegnitzer, Magnus Herbst y Thomas Glockner, 1492.

ESQUIVEL DE BARAHONA, Juan, Missarum... liber primus. Salamanca, Artus Tabernelius, 1608.

EZQUERRO ESTEBAN, Antonio, Villancicos policorales aragoneses del siglo XVII. Barcelona, Departamento de Musicología, Institución "Milá y Fontanals", Consejo Superior de Investigaciones Científicas, col. "Monumentos de la Música Española, LIX”, 2000.

EZQUERRO ESTEBAN, Antonio, “Tabula compositoria, partitura, chapa y borrador. Formas de anotar la polifonía y música instrumental en el ámbito hispánico durante el período barroco”, en Im Dienst der Quellen zur Musik: Festschrift Gertraut Haberkamp zum 65. Geburtstag / hrsg. von der Bischöflichen Zentralbibliothek Regensburg durch Paul Mai. Tutzing, Hans Schneider Verlag, 2002, pp. 259-274.

EZQUERRO ESTEBAN, Antonio, et alii (eds.): Música de la catedral de Barcelona a la Biblioteca de Catalunya: Compositors de la cort en els temps dels darrers Àustries i els primers Borbons. Barcelona, Biblioteca de Catalunya, 2009.

EZQUERRO ESTEBAN, Antonio, "José de Nebra entre España y la Nueva España: fuentes documentales de música - dimensión internacional - para su estudio”, en Lope de Barrientos. Seminario de Cultura, 3 (Cuenca, 2010 [2011]), pp.59-104.

EZQUERRO ESTEBAN, Antonio, "Recepción de la música de Georg Friedrich Händel en España: el caso del Archivo de Música de las Catedrales de Zaragoza y la intervención de los músicos Nebra”, en Recerca Musicològica, XX (Barcelona, en prensa).

EZQUERRO ESTEBAN, Antonio y GONZÁLEZ MARÍN, Luis Antonio, "Catálogo del Fondo Documental del siglo XVII del Archivo Musical de las Catedrales de Zaragoza (Zac)”, en Anuario Musical, 46 (Barcelona, 1991), pp. 127-171.

EZQUERRO ESTEBAN, Antonio, GONZÁLEZ MARÍN, Luis Antonio y GONZÁLEZ VALLE, José Vicente, "The Circulation of Music in Spain, 1600-1900: A Spanish Perspective", en Musical Life in Europe 1600-1900. Circulation, Institutions, Representation. The Circulation of Music. Volume II. The Circulation of Music in Europe 1600-1900. A Collection of Essays and case Studies. [RASCH, Rudolf (ed.)]. Berlín, BWV-Berliner Wiessenschafts Verlag, 2008, pp. 9-31.

EZQUERRO ESTEBAN, Antonio, GONZÁLEZ MARÍN, Luis Antonio y GONZÁLEZ VALLE, José Vicente (eds.), La Música en los Archivos de las Catedrales de Aragón. Zaragoza, Caja Inmaculada, 2008 b.

FERNÁNDEZ DE HUETE, Diego, Compendio numeroso de zifras armónicas, con theórica y práctica, para harpa de una orden, de dos órdenes, y de órgano. Madrid, Imprenta de Música, Primera parte 1702 y Segunda parte 1704 .

FREYTAG, Richard, et alii ["Felsberg Orgelbau”]: El órgano de Longares. Zaragoza/España 1699. Una restauración histórica. Zaragoza, Institución "Fernando El Católico", 1985.

GONZÁLEZ MARÍN, Luis Antonio, "El órgano y el acompañamiento en la música española del Barroco”, en Rolde, 58-59 (Zaragoza, 1991), pp. 45-52. 
GONZÁLEZ MARÍN, Luis Antonio, "El teatro musical español del siglo XVII y sus posibilidades de restauración”, en Anuario Musical, 48 (Barcelona, 1993), pp. 63-102.

GONZÁLEZ MARÍN, Luis Antonio, "Regir la capilla o el oficio de director antes de que existieran los directores", en Quodlibet , 46 (Alcalá de Henares, enero-abril 2010), pp. 81-117.

GONZÁLEZ MARÍN, Luis Antonio (dir.), [Los Músicos de Su Alteza. CD], Joseph Ruiz Samaniego. La vida es sueño... París, Alpha, col. "Ut pictura música”, 2009.

GONZÁlEZ MARÍN, Luis Antonio (dir.), [Los Músicos de Su Alteza. CD], José de Nebra: Amor aumenta el valor. París, Alpha, col. "Ut pictura música”, 2010.

GONZÁLEZ VALLE, José Vicente, et alii (eds.), Andrés Lorente: El Por qué de la Música. (Alcalá de Henares, Nicolás de Xamares, 1672). [Edición facsímil]. Barcelona, CSIC, col. "Textos Universitarios, 38", 2002.

GUILLÉN BERMEJO, Ma Cristina y RUIZ DE ELVIRA SERRA, Isabel (coords.), Catálogo de Villancicos y Oratorios en la Biblioteca Nacional. Siglos XVIII-XIX. Madrid, Biblioteca Nacional, Ministerio de Cultura, 1990.

GUZMÁN BRAVO, José Antonio, "Documentos inéditos para la restauración de los órganos históricos de la catedral metropolitana de Nuestra Señora de la Asunción, de México Tenochtitlán (16881736)", en Anuario Musical, 62 (Barcelona, 2007), pp. 125-169.

GUZMÁN, Jorge de, Curiosidades del canto llano. Madrid, Imprenta de Música, 1709.

HAYNES, Bruce, "Pitch", en The New Grove Dictionary of Music and Musicians. Vol. 19. Nueva York, Oxford University Press, 2001, pp. 793-802.

ISUSI FAGOAGA, Rosa, "Pedro Rabassa en la teoría musical del s. XVIII: algunos aspectos sobre instrumentos y voces según su guía para principiantes”, en Revista de Musicología, 20/1 (Madrid, 1997), pp. 401-416.

LINDLEY, Mark, “Temperaments”, en The New Grove Dictionary of Music and Musicians. Vol. 25. Nueva York, Oxford University Press, 2001, pp. 248-268.

LOBO DE BORJA, Alonso, Liber primus missarum. Madrid, Tipografía Regia, 1602.

LÓPEZ-CALO, José, “La controversia de Valls”, en Tesoro Sacro Musical, 51 (Madrid, 1968), pp. 11-14, 22-26 y 70-72, y 54 (Madrid, 1971), pp. 109-116.

MARTÍN MORENO, Antonio, El Padre Feijoo y las ideologías musicales del XVIII en España. Orense, Instituto de Estudios Orensanos "Padre Feijoo", 1976.

MARTÍN MORENO, Antonio, “Algunos aspectos del barroco musical español a través de la obra teórica de Francisco Valls (1665?-1747)”, en Anuario Musical, 31-32 (Barcelona, 1976-1977), pp. 157-194.

MARTÍN Y COLL, fray Antonio, Flores de música, obras y versos de varios organistas. Escriptas por fray Antonio Martín Coll organista de San Diego de Alcalá.Año de 1706. Madrid, 1706; Ms., E: Mn, M 1357.

MARTÍN Y COLL, fray Antonio, Pensil deleitoso de suabes flores de mussica. Recogidas de varios organistas por F. Antonio Martín organista de S. Diego de la ciudad de Alcalá, año 1707, Estevan de Yusta Calvo. Madrid, 1701; Ms., E: Mn, M 1358. 
MARTÍN Y COLL, fray Antonio, Huerto ameno de varias flores de música recogidas de muchos organistas por fray Antonio Martín, 1708. Madrid, 1708; Ms., E: Mn, M 1359.

MARTÍN Y COLL, fray Antonio, Huerto ameno de varias flores de música recogidas de varios organistas por fray Antonio Martín, año 1709 de Estevan Yusta Calvo. Madrid, 1709a; Ms., E: Mn, M 1360.

MARTÍN Y COLL, fray Antonio, Ramillete oloroso. Suabes flores de música para órgano. Madrid, 1709b; Ms., E: Mn, M 2267.

MARTÍN Y COLL, fray Antonio, Arte de canto llano, y breve resumen de sus principales reglas, para cantores de choro; dividido en dos libros; en el primero, se declara lo que pertenece à la theórica; y en el segundo, lo que se necessita para la práctica, y las entonaciones de los psalmos con el órgano... Madrid, Vda. de Juan Garcia Infançon, 1714; ... Y añadido en esta segunda impression con algunas advertencias, y el arte de canto de organo. Madrid, Imprenta de Música (Bernardo Peralta), 1719.

MINGUET E YROL, Pablo (ed.), Reglas y advertencias generales que enseñan el modo de tañer todos los instrumentos mejores y más usuales, como son la guitarra, tiple, vandola, cythara, clavicordio, órgano, harpa, psalterio, bandurria, violín, flauta travesera, flauta dulce, y la flautilla. Madrid, [¿Joaquín Ibarra?], 1752-1754.

Missale Caesaraugustanum. Zaragoza, Pablo Hurus, 1485.

MONTANOS, Francisco, Arte de canto llano, con entonaciones comunes de coro y altar. [Valladolid, Diego Fernández de Córdoba, 1592 y 1594]. [Reedición — ampliada-:] Madrid, Imprenta de Música, 1712, 1728 y 1734.

NASSARRE, fray Pablo, Fragmentos músicos. Reglas generales, y muy necessarias para canto llano, canto de organo, contrapunto, y composicion. (Zaragoza, T. G. Martinez, 1683) ... Repartidos en quatro tratados... y aora nuevamente añadido el ultimo tratado por el mismo autor; y juntamente exemplificados con los caracteres musicos de que carecia. Madrid, Joseph de Torres, 1700.

NASSARRE, fray Pablo, Escuela música según la práctica moderna. $1^{\mathrm{a}}$ Parte, Zaragoza, Herederos de Diego de Larumbe, 1724 y 2a Parte, Zaragoza, Herederos de Manuel Román, 1723. [Edición facsímil: Zaragoza, Institución "Fernando el Católico", 1980].

PAVIA I SIMÓ, Josep, La Música en Cataluña en el siglo XVIII. Francesc Valls (1671 c-1747). Barcelona, Departamento de Musicología, Institución "Milá y Fontanals", Consejo Superior de Investigaciones Científicas, col. "Monumentos de la Música Española, LIII”, 1997.

PAVIA I SIMÓ, Josep (ed.), Francesc Valls: Mapa Armónico Práctico (1742a). [Edición en facsímil del ejemplar manuscrito conservado en la Biblioteca de la Universidad de Barcelona (Manuscrito 783)]. Barcelona, Departamento de Musicología, Institución "Milá y Fontanals”, Consejo Superior de Investigaciones Científicas, col. "Textos Universitarios, 37”, 2002.

RAMEAU, Jean Philippe, Traité de l'harmonie réduite à ses principes naturels. París, Jean-BaptisteChristophe Ballard, 1722.

RAVAL, Sebastián, Motecta selecta organo accomodata, quae partim tribus, partim quatuor, partim quinq; unum sex, alteru[m] octo vocibus paribus concinuntur... quibus est addita operum divisio, pro organo. Palermo, Giovanni Antonio de Franceschi, 1600. 
RIMONTE, Pedro, Parnaso español de madrigales y villancicos a quatro cinco y seys. Amberes, Pedro Phalesio, 1614.

ROSA MONTAGUT, M M Amparo, "Música y fiesta barroca: celebraciones en Tortosa en honor a Felipe V (1701)", en Anuario Musical, 59 (Barcelona, 2004), pp. 85-114.

ROSA MONTAGUT, Ma Amparo, "Una aproximación a la capilla de música de la catedral de Tortosa (Tarragona): 1700-1750”, en Anuario Musical, 61 (Barcelona, 2006), pp. 155-165.

ROSA MONTAGUT, Ma Amparo, José Pradas Gallén (1689-1757): Tres villancets a vuit veus amb violins. La tierra llora afligida, Cantad serafines, Trono sagrado de luces. Barcelona, Tritó-IVMGeneralitat Valenciana, 2008.

ROSA MONTAGUT, Ma Amparo, "El archivo musical de la Catedral de Tortosa (Tarragona): Villancicos para la traslación de la Santa Cinta”, en Actas del XXIV Congreso de la Asociación de Archiveros de la Iglesia en España: Reliquias y Relicarios en los Archivos de la Iglesia, 34 (Oviedo, 2011), pp. 471-494.

ROSA MONTAGUT, Ma Amparo (dir.), [Harmonia del Parnàs. CD], Arda el ayre. (Villancicos a la Verge de la Cinta). Josep Escorihuela (1674-1743), y Josep Pradas (1689-1757). Barcelona, La mà de Guido, 2006a.

ROSA MONTAGUT, Ma Amparo (dir.), [Harmonia del Parnàs. CD], Pere Rabassa (1683-1767). Requiem. Barcelona, La mà de Guido, 2006b.

ROSA MONTAGUT, M Amparo (dir.), [Harmonia del Parnàs. CD], José Pradas Gallén (1689-1757). La tierra llora afligida. [Villancicos y obra en latín]. Valencia, Institut Valencià de la Música (Generalitat Valenciana), col. "Patrimonio Musical Valenciano, 8", 2008.

ROSA MONTAGUT, Ma Amparo (dir.), [Harmonia del Parnàs. CD], Salve Regina. Pedro Rabassa y Pascual Fuentes. Valencia, TEMPUS Centro de Investigación y Difusión Musical, 2010.

ROSA MONTAGUT, Ma Amparo (dir.), [Harmonia del Parnàs. CD], Bárbaro. Francisco Hernández Illana y Francesco Corradini. Valencia, TEMPUS Centro de Investigación y Difusión Musical, 2012.

RUIZ DE ELVIRA SERRA, Isabel (coord.), Catálogo de Villancicos de la Biblioteca Nacional. Siglo XVII. Madrid, Biblioteca Nacional, Ministerio de Cultura, 1992.

SANZ, Gaspar, Instrucción de música sobre la guitarra española y método de sus primeros rudimentos hasta tañerla con destreza. Zaragoza, Herederos de Diego Dormer, 1674 (8a edición, 1697).

SAURA BUIL, Joaquín, Diccionario Técnico-Histórico del órgano en España. Barcelona, CSIC, col. “Textos Universitarios, 34”, 2001.

SELMA Y SALAVERDE, Bartolomé de, Primo libro de canzoni, fantasie \& correnti da suonnare ad una, due, tre e quatro col basso continuo. Venecia, Bartolomeo Magni, 1638.

SIEMENS HERNÁNDEZ, Lothar, "Contribución a la bibliografía de las fuentes de la cuestión Valls”, en Anuario Musical, 31-32 (Barcelona, 1976-1977), pp. 195-223.

SOLER, Antonio, Llave de la modulación y antigüedades de la música. Madrid, Joaquín Ibarra, 1762.

TORRENTE, Álvaro y MARÍN, Miguel Ángel, Pliegos de villancicos en la British Library (Londres) y la University Library (Cambridge). Kassel, Reichenberger, 2000. 
TORRES Y MARTÍNEZ BRAVO, José de, Reglas generales de acompañar, en organo, clavicordio, y harpa, con solo saber cantar la parte, o un baxo en canto figurado. [...] Añadido aora un nuevo tratado, donde se explica el modo de acompañar las obras de musica, segun el estilo italiano. Madrid, Imprenta de Música, [1702 y] 1736. [Edición facsímil: Madrid, Arte Tripharia, 1983].

TOSCA, Tomás Vicente, Compendio mathemático en que se contienen todas las materias más principales de las ciencias que tratan de la cantidad. Valencia, Antonio Bordazar, 1709.

ULlOA, Pedro de, Musica Universal o Principios Universales de la Musica. Madrid, Bernardo Peralta, 1717.

VALERO SUÁREZ, José Ma y RAINOLTER-WETTER, Cristina y Claudio (comisarios), Órganos históricos restaurados. Monasterio de Veruela del 21 Mayo al 25 Agosto de 1991. [Catálogo de la exposición, "Joyas de un Patrimonio"]. Zaragoza, Arzobispado de Zaragoza-Diputación de ZaragozaObispado de Tarazona, 1991.

VICTORIA, Tomás Luis de, Missae, Magnificat, Motecta, Psalmi. Madrid, Tipografía Regia, 1600.

VIVANCO, Sebastián de, Liber Magnificarum. Salamanca, Artus Taberniel, 1607.

Recibido: 05/03/2012

Aceptado: 21/02/2013 